\title{
Pathophysiology of Experimental Glomerulonephritis in Rats
}

\author{
Marjorie E. M. Allison, Curtis B. Wilson, and Carl W. Gottschalk, with the \\ technical assistance of SARAH K. DAvis \\ From the Department of Medicine, University of North Carolina School of \\ Medicine, Chapel Hill, North Carolina 27514 and the Department of Experimental \\ Pathology, Scripps Clinic and Research Foundation, La Jolla, California 92037
}

\begin{abstract}
A B S T R A C T Micropuncture, clearance, immunofluorescence and light microscopy techniques were used to study kidney structure and single nephron function in rats with autologous immune complex nephritis (AICN), a membranous glomerulonephritis developing over 5 to $20 \mathrm{mo}$, in the more acute and proliferative glomerular basement membrane (GBM) nephritis and in controls. Both models are known to have clinical counterparts in human disease. Kidney functional abnormalities correlated with the degree of architectural derangement. In both AICN and anti-GBM nephritis filtration fraction fell in direct proportion to the fall in glomerular filtration rate (GFR), renal plasma flow being unchanged. Fractional electrolyte excretion increased as the GFR fell. Despite marked heterogeneity of single nephron filtration rate (SNGFR) (AICN, 5$93 \mathrm{nl} / \mathrm{min}$; anti-GBM, $0-50 \mathrm{nl} / \mathrm{min}$ ) and of proximal tubular hydrostatic pressure $(4-48 \mathrm{~mm} \mathrm{Hg})$, each nephron showed almost complete glomerulotubular balance, absolute reabsorption to the late proximal convolution varying directly with filtration rate. In addition SNGFR could be related both to proximal intratubular hydrostatic pressure and to calculated glomerular capillary pressure $(\mathrm{Pg})$, being lowest in those nephrons with the highest intratubular pressure. Nephrons with very high filtration rates did not apparently reach filtration equilibrium. Mean SNGFR was significantly lower in the anti-GBM group, while calculated $\mathrm{Pg}$ was the same in both. This probably reflects the acute and diffuse involvement of the antiGBM lesion with different filtration characteristics from
\end{abstract}

Dr. Allison was a Career Investigator Fellow, American Heart Association. Her present address is the Renal Unit, Glasgow Royal Infirmary, Glasgow, Scotland.

Dr. Gottschalk is a Career Investigator, American Heart Association.

Received for publication 22 June 1973 and in revised form 8 October 1973. the more chronic AICN disease. Tubular damage was more marked in AICN, and extraction of $p$-aminohippurate was reduced in this group.

\section{INTRODUCTION}

Since the classical description by Richard Bright in 1827 of the clinical effects of chronic renal disease a multitude of detailed studies have been made of whole kidney function in such patients (1-5). The painstaking microdissection studies of Oliver (6) have shown that such kidneys are "a heterogeneous collection of various and disparate organs, the abnormal nephrons of chronic renal disease" (7). Impressive overall functional renal adaptation accompanies these marked structural changes (8-11). Information on the function of individual structurally altered nephrons, however, is sparse and apparently contradictory (1217).

We have used micropuncture, clearance, immunofluorescence and light microscopy techniques to study kidney structure and single nephron function in rats with two forms of immunologically induced glomerulonephritis.

Firstly, autologous immune complex or Heymann's nephritis $(\operatorname{AICN})^{1}(18,19)$ was chosen as a model resembling human membranous glomerulonephritis.

${ }^{1}$ Abbreviations used in this paper: $\mathrm{ADH}$, antidiuretic hormone; AICN, autologous immune complex nephritis; antiGBM, antiglomerular basement membrane; BUN, blood urea nitrogen; C, clearance; CFA, complete Freund's adjuvant; E, extraction; EFP, effective filtration pressure; FF, filtration fraction; GBM, glomerular basement membrane; GFR, glomerular filtration rate; PAH, $p$-aminohippurate; PAS, periodic acid-Schiff; PBS, $0.01 \mathrm{M}$ phosphatebuffered $0.15 \mathrm{M} \mathrm{NaCl}, \mathrm{pH} 7.0 ; \mathrm{Pg}$, glomerular capillary hydrostatic pressure; RPF, renal plasma flow; RTA, renal tubular antigen; SNGRF, single nephron glomerular filtration rate; TBM, tubular basement membrane. 
Secondly, antiglomerular basement membrane (AntiGBM) nephritis (20) was studied as a more acute, proliferative model of human glomerular injury.

\section{METHODS}

AICN. $50100 \mathrm{~g}$ male Wistar rats (Research Animals Inc., Braddock, Pa.) were given rear foot pad injections totalling $12.5 \mathrm{mg}$ of partially purified rat renal tubular antigen (RTA) in $0.25 \mathrm{ml}$ complete Freund's adjuvant (CFA) containing $2.5 \mathrm{mg}$ of Mycobacterium butyricum (Difco Laboratories, Detroit, Mich.). Intraperitoneal injections (18) were not used because we wished to avoid granulomatous peritonitis with subsequent micropuncture difficulties. RTA was prepared by a slight modification of that described by Edgington, Glassock, and Dixon (21). A suspension of Wistar and Sprague Dawley rat renal cortex (Pel-Freez Biologicals, Inc., Rogers, Ark.) was prepared by passing cortical fragments through a 150 mesh stainless steel screen. Basement membrane and cellular fragments were removed by low speed centrifugation (150 $g$ ). The supernate was then centrifuged at 78,000 $g$ for 30 $\mathrm{min}$ and the resultant sediment washed two times in PBS (0.01 $\mathrm{M}$ phosphate buffered, $0.15 \mathrm{M} \mathrm{NaCl}, \mathrm{pH} \mathrm{7.0)}$ and lyophilized.

In 15 rats a second dose of $12.5 \mathrm{mg}$ of RTA in CFA was given intradermally 51 days (five rats), 93 days (three rats), and 187 days (seven rats) later. In 28 rats, two additional 12.5-mg doses were given 51 and 106 days (19 rats) and 93 and 187 days (nine rats) after the initial injection. 24-h urinary protein excretion rates were used to follow the onset of overt glomerulonephritis. Determination of urine protein concentration was made by using either the Biuret technique or salicylsulphonic acid. Clearance and micropuncture studies were done 5-20 mo after the first injection.

Anti-GBM glomerulonephritis. Rabbit anti-rat GBM antibody was induced by biweekly injections (foot pads and intradermally) of $10-30 \mathrm{mg}$ of rat GBM (22) in CFA. Antibody production was quantitated by the paired-label isotope technique $(23,24)$.

Male Wistar rats $(100-150 \mathrm{~g})$ were given $1.75-2.25 \mathrm{ml}$ (five rats) and $1.5-2.2 \mathrm{ml}$ (five rats) rabbit anti-rat GBM antibody containing 113 and $130 \mu \mathrm{g}$ of kidney fixing antibody per $\mathrm{ml}$, respectively, and were studied 10-38 days later. Intensified glomerular lesions were produced by enhancing the recipients immune response to the heterologous antiGBM antibody by administering $1.8 \mathrm{mg}$ of rabbit IgG in incomplete Freund's adjuvant 3 days before receipt of antiGBM antibody (25).

Controls. 17 male Wistar rats, of a similar age to the A.ICN animals, were used as controls. In eight that were 4-wk old, CFA alone was injected intradermally in the proportions given above, and injections were repeated 93 days later in four of them. The remaining nine rats received no injections.

Clearance and micropuncture studies. Clearance and, in most instances, micropuncture studies were made in 24 rats with $A I C N$, in all 10 rats with anti-GBM nephritis, and in 12 control rats. All were deprived of food but not of water overnight before study, and were anesthetized by intraperitoneal injection of sodium pentobarbital, $50 \mathrm{mg} / \mathrm{kg}$ body wt. The rats were prepared for micropuncture as previously described $(26)$, isotonic saline, $0.5 \%$ of body wt, being given during surgery to replace fluid losses. Both ureters were cannulated with $\mathrm{PE} 10$ polyethylene tubing.
Blood pressure was recorded continuously from the carotid artery by using a Statham P23Db transducer (Statham Instruments, Inc., Oxnard, Calif.) and a Beckman Dynograph recorder (Beckman Instruments, Inc., Fullerton, Calif.).

All rats were studied during hydropenia, modified Ringer's solution $(\mathrm{NaCl}, 0.85 \mathrm{~g} / 100 \mathrm{ml} ; \mathrm{KCl}, 0.042 \mathrm{~g} / 100 \mathrm{ml}$; $\mathrm{CaCl}_{2}, 0.025 \mathrm{~g} / 100 \mathrm{ml} ; \mathrm{NaHCO}_{3}, 0.02 \mathrm{~g} / 100 \mathrm{ml}$ ) being given i.v. at the rate of $0.4 \mathrm{ml} / 100 \mathrm{~g}$ body $\mathrm{wt} / \mathrm{h}$, together with $d$-aldosterone (Ciba Pharmaceutical Company, Summit, N. J.), vasopressin (Parke, Davis \& Co., Detroit, Mich), $\left[{ }^{3} \mathrm{H}\right]$ methoxy inulin (International Chemical and Nuclear Corporation, Burbank, Calif.) and in most instances $\left[{ }^{14} \mathrm{C}\right] p$-aminohippurate $(\mathrm{PAH})$ (New England $\mathrm{Nu}-$ clear Corp., Boston, Mass.). In those rats in which intrarenal pressure measurements were made a priming dose of $3 \mu \mathrm{g}$ of $d$-aldosterone, $60 \mu \mathrm{Ci}\left[{ }^{3} \mathrm{H}\right]$ inulin, and $2 \mu \mathrm{Ci}$ $\left.{ }^{[14} \mathrm{C}\right] \mathrm{PAH}$ was followed by infusion of $d$-aldosterone, 2.4 $\mu \mathrm{g} / \mathrm{h}$; antidiuretic hormone (ADH), $0.03 \mu \mathrm{g} / \mathrm{h} ;\left[{ }^{1 \mathrm{~h}} \mathrm{C}\right] \mathrm{PAH}$, 5-7 $\mu \mathrm{Ci} / \mathrm{h}$; and $\left[{ }^{3} \mathrm{H}\right]$ inulin at a rate of $20 \mu \mathrm{Ci} / 100 \mathrm{~g}$ body wt/h. When proximal tubular $F / P$ inulin levels were to be measured this infusion was increased to $40-80 \mu \mathrm{Ci}\left[{ }^{3} \mathrm{H}\right]-$ inulin $/ 100 \mathrm{~g}$ body $\mathrm{wt} / \mathrm{h}$.

Three consecutive timed urine collections, each lasting approximately 45-60 min, were made from both kidneys. Blood $(<30 \mu 1)$ was obtained from the carotid artery and (L) renal vein at approximately 45-min intervals for measurement of hematocrit, $\left[{ }^{3} \mathrm{H}\right]$ inulin, and $\left[{ }^{14} \mathrm{C}\right] \mathrm{PAH}$ levels. Clearances were determined as previously described (27). Glomerular filtration rate (GFR) was calculated separately for the left and right kidneys, renal plasma flow (RPF) for the left kidney only.

In those rats not given $\left[{ }^{14} \mathrm{C}\right] \mathrm{PAH}$ the left $\mathrm{RPF}$ was calculated as follows :

$$
R P F=\frac{V(U-R)}{A-R}
$$

where $\mathrm{V}=$ urine flow rate and $\mathrm{U}, \mathrm{A}$, and $\mathrm{R}=$ inulin concentration in urine, arterial plasma, and renal venous plasma, respectively.

In those rats given $\left[{ }^{14} \mathrm{C}\right] \mathrm{PAH}$ the $\mathrm{RPF}$ was calculated as

$$
\frac{C_{P A H}}{E_{P A B}}
$$

where $\mathrm{C}=$ clearance and $\mathrm{E}=$ extraction.

Two groups of micropuncture experiments were carried out. In the first series (six AICN, five anti-GBM, and three control rats) the kidney was bathed with mineral oil heated to $36 \pm 1^{\circ} \mathrm{C}$. Sharpened siliconized glass pipettes, external tip diameter 4-6 $\mu \mathrm{m}$, filled with isotonic saline colored with lissamine green ( $\mathrm{K}$ and $\mathrm{K}$ Laboratories, Inc., Plainview, N. Y.) were used to puncture a superficial proximal convolution, and the free flow hydrostatic pressure was measured by using the "Landis" technique (26). Simultaneously the last loop of the proximal tubule visible on the surface of the kidney was identified by following the passage of the lissamine green colored saline. This last convolution was later punctured with a sharpened siliconized glass pipette, external tip diameter 11-12 $\mu \mathrm{m}$, and a mineral oil block, 4-5 tubular diameters in length was injected. Tubular fluid was then collected, controlled suction being used to keep the oil block in place and the tubular diameter constant if this was at all possible. The sample was pulled into the straight part of the collection pipette by using toluene, the length and diameter measured by using an eyepiece micrometer, and the volume calculated. The 
whole sample was then discharged into counting fluid. The following calculations were made:

$\mathrm{SNGFR}=\mathrm{F} / \mathrm{P}$ inulin $\times$ tubular flow rate in $\mathrm{nl} / \mathrm{min}$

Percent reabsorption to the late proximal convolution

$$
=\left(1-\frac{1}{\mathrm{~F} / \mathrm{P} \text { inulin }}\right) \times 100
$$

Absolute reabsorption $=$ fractional reabsorption

$\times \mathrm{SNGFR} \mathrm{nl} / \mathrm{min}$

In the second group (15 AICN, five anti-GBM, and seven control rats) the kidney was bathed with isotonic saline heated to $36 \pm 1^{\circ} \mathrm{C}$ in order to allow the use of an electronic servo-nulling device for measurement of hydrostatic pressure as previously described (28). Sharpened, siliconized glass pipettes, external tip diameter 3-5 $\mu \mathrm{m}$, filled with $2 \mathrm{M} \mathrm{NaCl}$ were used to measure hydrostatic pressure in proximal tubules during free flow, in the large efferent arterioles or stars, in intermediate vessels, which are large diameter straight vessels and which often arise from stars, and in the larger peritubular capillaries.

In an attempt to estimate glomerular capillary hydrostatic pressure $(\mathrm{Pg})$, the stop flow hydrostatic pressure was also measured (28). The $\mathrm{Pg}$ was estimated as the sum of the stop flow pressure and the afferent oncotic pressure. In four rats with AICN and in five rats with anti-GBM disease timed collections of proximal tubular fluid from easily accessible proximal convolutions for calculation of SNGFR were made immediately before measuring the stop flow pressure in the same nephron. Inadvertent contamination of the tubular fluid sample with superficial saline is not important in this instance, since we are interested only in filtration rate. Hence we have SNGFR, free flow hydrostatic pressure, and an estimate of glomerular hydrostatic pressure in individual superficial nephrons.

Efferent arteriolar protein concentration in these nephrons was calculated by using the whole kidney filtration fraction (FF) (29).

Efferent arteriolar protein concentration

$$
=\frac{\text { Afferent arteriolar protein concentration }}{1-\text { whole kidney FF }}
$$

Arterial plasma and serum protein concentrations were measured before, during, and at the end of each experiment by an adaptation of the Lowry technique (30) using rat serum protein standards. These values were used to calculate oncotic pressure ( $\pi \mathrm{a})$ by the Landis and Pappenheimer (31) equation:

$$
\pi \mathrm{a}=2.1 \mathrm{~Pa}+0.16 \mathrm{~Pa}^{2}+0.009 \mathrm{~Pa}^{3}
$$

In order to validate this equation for rat serum the oncotic pressure was also measured directly in samples from six AICN and three control rats (G. Navar, University of Mississippi Medical Center, Jackson, Miss.). The calculated mean value of $18.9 \pm 1.41$ is not significantly different from that obtained directly, $20.2 \pm 3.03 \mathrm{~mm} \mathrm{Hg}$.

The afferent and efferent effective filtration pressures (EFP) were calculated as follows :

$$
\begin{aligned}
& \text { Afferent EFP }=P g-(\text { ITP }+\pi \mathrm{a}) \\
& \text { Efferent EFP }=\mathrm{Pg}-(\mathrm{ITP}+\pi \mathrm{e})
\end{aligned}
$$

where $\pi \mathrm{a}$ is the afferent oncotic pressure, $\pi \mathrm{e}$ the calculated efferent oncotic pressure, and ITP the intratubular pressure.
These equations assume that the oncotic pressure of the tubular fluid is so small as to be insignificant, a situation which is true for the normal undamaged nephron (32). We have not measured the concentration of protein in the glomerular filtrate of the diseased nephron in this study, but Lewy and Pesco (33) and Oken, Cotes, and Mende (34) using animals with aminonucleoside damaged kidneys and proteinuria have reported an albumin concentration of only $2.7-234 \mathrm{mg} / 100 \mathrm{ml}$ in the glomerular filtrate, and it seems unlikely that tubular fluid protein levels in our study were high enough to exert a significant oncotic pressure.

Blood was taken terminally for estimation of blood urea nitrogen (BUN), measured on a Technicon autoanalyzer (Technicon Corporation, Ardsley, N. Y.) by a modification of the carbamido-diacetyl fraction as applied to the determination of urea nitrogen and cholesterol. Urine and plasma electrolytes were measured on an IL direct reading flame photometer (Instrumentation Laboratories Inc., Watertown, Mass.). Fractional electrolyte excretion was calculated without use of the Donnan Factor.

Microinjection studies. In order to examine the permeability of the nephrons to inulin a separate series of microinjection experiments (35) were performed in nine rats with anti-GBM nephritis and in two with AICN, prepared as previously described. For microinjection studies they were infused with $5 \%$ mannitol in isotonic saline at 3.1 $\mathrm{ml} / \mathrm{h}$ and PE 50 catheters were placed in both ureters. A measured volume $(0.8-3.5 \mathrm{nl})$ of $\left[{ }^{3} \mathrm{H}\right]$ inulin (International Chemical and Nuclear Corporation) colored with nigrosin, was injected slowly over $30-60 \mathrm{~s}$ into superficial proximal tubules, 8-min urine collections being made from each kidney for 24-120 min thereafter into liquid scintillation counting fluid (PCS, Amersham/Searle, Arlington Heights, III.). The total percentage of the measured injectate recovered from each kidney was calculated. The hydrostatic pressure in each nephron injected was measured by using a servo-nulling pressure apparatus.

Immunopathologic studies." At the end of each experiment, both kidneys from each animal were weighed. The kidneys were bisected along the anterior-posterior axis so as to assure adequate assessment of the entire thickness of the cortex, medulla, and papilla. One half of the right kidney was snap frozen (liquid nitrogen or a dry ice-alcohol bath) to await immunofluorescent studies. Cryostat sections from this kidney were overlayed with fluorescein isothiocyanate-conjugated IgG fractions of antiserum monospecific in immunodiffusion for rat $\mathrm{IgG}$ and $\mathrm{C} 3$, for direct immunofluorescent study (36). The remainder of the kidney tissue was fixed in Bouin's solution and postfixed in $50 \%$ ethyl alcohol. Sagittal sections of the entire bisected surface were obtained after paraffin embedding. The sections were stained with hematoxylin-eosin and periodic acid-Schiff (PAS) for light microscopy.

All sections were studied as unknowns. The pattern of immunoreactant ( $\mathrm{IgG}, \mathrm{C} 3$ ) deposition was noted and semiquantitated by using a $0-4$ scale (37). The histologic sections were graded 0 to $4+$ for the following categories: glomerular hypercellularity, necrosis, sclerosis; GBM thickening; overall architectural derangement; interstitial infiltration; tubular atrophy, luminal cells, casts; and thickening of tubular basement membrane (TBM). The number of polymorphonuclear leukocytes per glomerulus was recorded as well as the percentage of glomeruli exhibiting crescent formation. Vessels were graded similarly $(0-4+)$ for degree of endothelial proliferation, duplication of the elastica and medial hypertrophy. Perivascular infiltration 
was generally included in the general category of interstitial infiltration. Since the micropunctures studies of necessity produced data from superficial nephrons, careful attention was given any possible variation in immunopathologic changes throughout the thickness of the cortex.

\section{RESULTS}

\section{General characteristics}

We attempted to induce AICN in a total of 50 male Wistar rats aged approximately 1 mo. 48/50 rats (96\%) had histological evidence of glomerulonephritis when examined 5-20 mo after 1-3 intradermal injections of RTA; 39 of 46 studied $(85 \%)$ had proteinuria exceeding $100 \mathrm{mg}$ per day. Only $2 / 17$ of similarly aged control rats $(13 \%)$ ultimately developed proteinuria greater than $100 \mathrm{mg}$ per day, when aged $17 \mathrm{mo}$ as previously described (37). None of the control rats given CFA alone (8/17) developed proteinuria greater than $60 \mathrm{mg}$ per day, although this has been reported as causing significant proteinuria in previous studies $(38,39)$. Fig. 1 shows the varying rates of development of proteinuria in 19 rats with AICN in which this was followed serially and in controls. There was no relationship between the total number of antigen injections given and the subsequent degree of proteinuria, the greatest and most rapidly developing proteinuria ( $885 \mathrm{mg}$ per day) being found in a rat given a single injection of RTA.

All ten rats given anti-GBM antibody and subsequently studied by micropuncture developed significant proteinuria, so that when studied in the autologous phase 10-38 days later (mean, 20 days) all had proteinuria in excess of $100 \mathrm{mg}$ per day.

Table I compares the serum protein, BUN, and cholesterol concentrations according to the final degree of proteinuria measured in the AICN, anti-GBM, and control rats. There was no evidence of hypoproteinemia in the rats with AICN, even in those with proteinuria greater than $400 \mathrm{mg}$ per day. In the more acute antiGBM nephritis group, however, mean serum protein

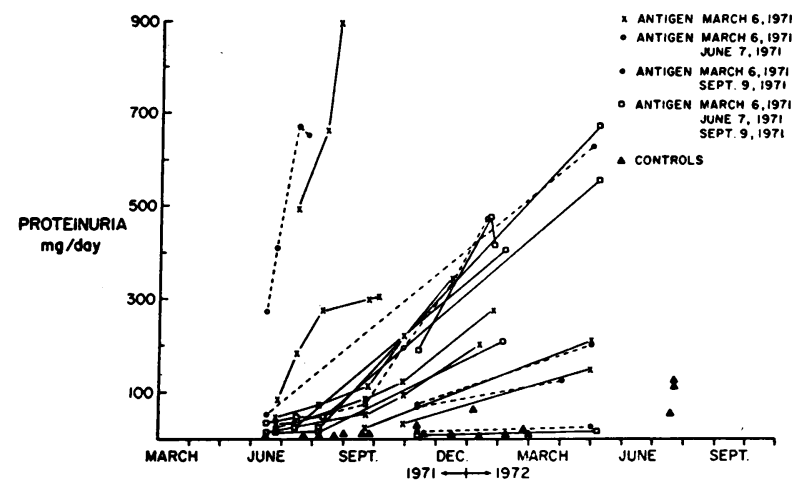

FIGURE 1 Development of proteinuria after one to three injections of RTA in 19 rats with AICN and in control rats of a similar age.

levels were significantly reduced below that of the controls.

The general characteristics of that portion of the total group in which detailed clearance and micropuncture studies were later carried out (24 rats with AICN,

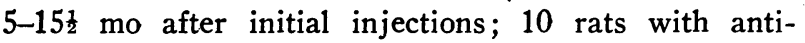
GBM nephritis, 10-38 days after injection; and 12 control animals) were similar. Daily protein excretion rates varied from 15 to $885 \mathrm{mg}$ (mean $357 \mathrm{mg} \pm 238$ $\mathrm{SD}$ ) in AICN and from 137 to $570 \mathrm{mg}$ (mean $356 \mathrm{mg}$ $\pm 145 \mathrm{SD}$ ) in anti-GBM nephritis. $24 \mathrm{~h}$ urine volume was significantly increased in AICN rats (controls $12.7 \mathrm{ml} \pm 4.0 \mathrm{SD}$, AICN $23.7 \mathrm{ml} \pm 11 \mathrm{SD}, P<0.001$ ). Mean plasma protein concentration was significantly reduced, however, only in the anti-GBM nephritis group (controls $5.68 \mathrm{~g} / 100 \mathrm{ml} \pm 0.36 \mathrm{SD}$, Anti-GBM $4.88 \pm 0.70 \mathrm{SD}, P<0.02$ ). None were edematous, although mean hematocrits were significantly reduced (controls $48.6 \% \pm 3.5 \mathrm{SD}, \mathrm{AICN} 44.4 \% \pm 5.4 \mathrm{SD}, P$ $<0.05$; Anti-GBM $41.2 \% \pm 5.6 \mathrm{SD}, P<0.001)$. All had hypercholesterolemia. Mean BUN concentration was significantly higher than in control rats only in anti-GBM nephritis (controls $18-44.5 \mathrm{mg} / 100 \mathrm{ml}$, mean

TABLE I

Relationship of Proteinuria to Serum BUN, Cholesterol, and Protein Concentrations in Control and Glomerulonephritic Rats

\begin{tabular}{|c|c|c|c|c|c|c|c|c|c|c|c|c|}
\hline \multirow[b]{2}{*}{ Proteinuria } & \multicolumn{4}{|c|}{$\begin{array}{c}\text { AICN } \\
\text { Age 6-21 mo }\end{array}$} & \multicolumn{4}{|c|}{$\begin{array}{c}\text { Controls } \\
\text { Age 5-17 mo }\end{array}$} & \multicolumn{4}{|c|}{$\begin{array}{l}\text { Anti-GBM } \\
\text { Age 2-3 mo }\end{array}$} \\
\hline & $n$ & BUN & Cholesterol & $\begin{array}{l}\text { Serum } \\
\text { protein }\end{array}$ & $\boldsymbol{n}$ & BUN & Cholesterol & $\begin{array}{l}\text { Serum } \\
\text { protein }\end{array}$ & $n$ & BUN & Cholesterol & $\begin{array}{l}\text { Serum } \\
\text { protein }\end{array}$ \\
\hline$m g / d a y$ & & $m g / 100 m l$ & $m g / 100 \mathrm{ml}$ & $\mathrm{g} / 100 \mathrm{ml}$ & & $m g / 100 m l$ & $\mathrm{mg} / 100 \mathrm{ml}$ & $\mathrm{g} / 100 \mathrm{ml}$ & & $\mathrm{mg} / 100 \mathrm{ml}$ & $\mathrm{mg} / 100 \mathrm{ml}$ & $\mathrm{g} / 100 \mathrm{ml}$ \\
\hline $0-50$ & 5 & $22.8 \pm 7.6$ & $69.6 \pm 35.7$ & $5.89 \pm 0.44$ & 12 & $27.7 \pm 9.1$ & $76.5 \pm 23.4$ & $5.77 \pm 0.35$ & - & - & - & - \\
\hline $50-100$ & 2 & 22.0 & 120.0 & 5.78 & 3 & $30.7 \pm 16.2$ & $84.5 \pm 30.4$ & $5.84 \pm 0.06$ & - & - & - & - \\
\hline $100-200$ & 7 & $26.9 \pm 9.84$ & $108.3 \pm 28.2$ & $5.97 \pm 0.59$ & 2 & 11.0 & 123.5 & 5.90 & 1 & 31 & 114 & 5.88 \\
\hline $200-400$ & 17 & $19.3 \pm 13.7$ & $168.6 \pm 57.8$ & $5.67 \pm 0.31$ & - & - & - & - & 4 & $40.1 \pm 12.9$ & $216.8 \pm 70.7$ & $5.06 \pm 0.50$ \\
\hline $400+$ & 15 & $31.1 \pm 12.7$ & $237.4 \pm 88.3$ & $5.66 \pm 0.56$ & - & - & - & - & 5 & $50.3 \pm 13.1$ & $244.0 \pm 68.4$ & $4.54 \pm 0.86$ \\
\hline
\end{tabular}

$n=$ number of rats. All figures are mean \pm SD. 

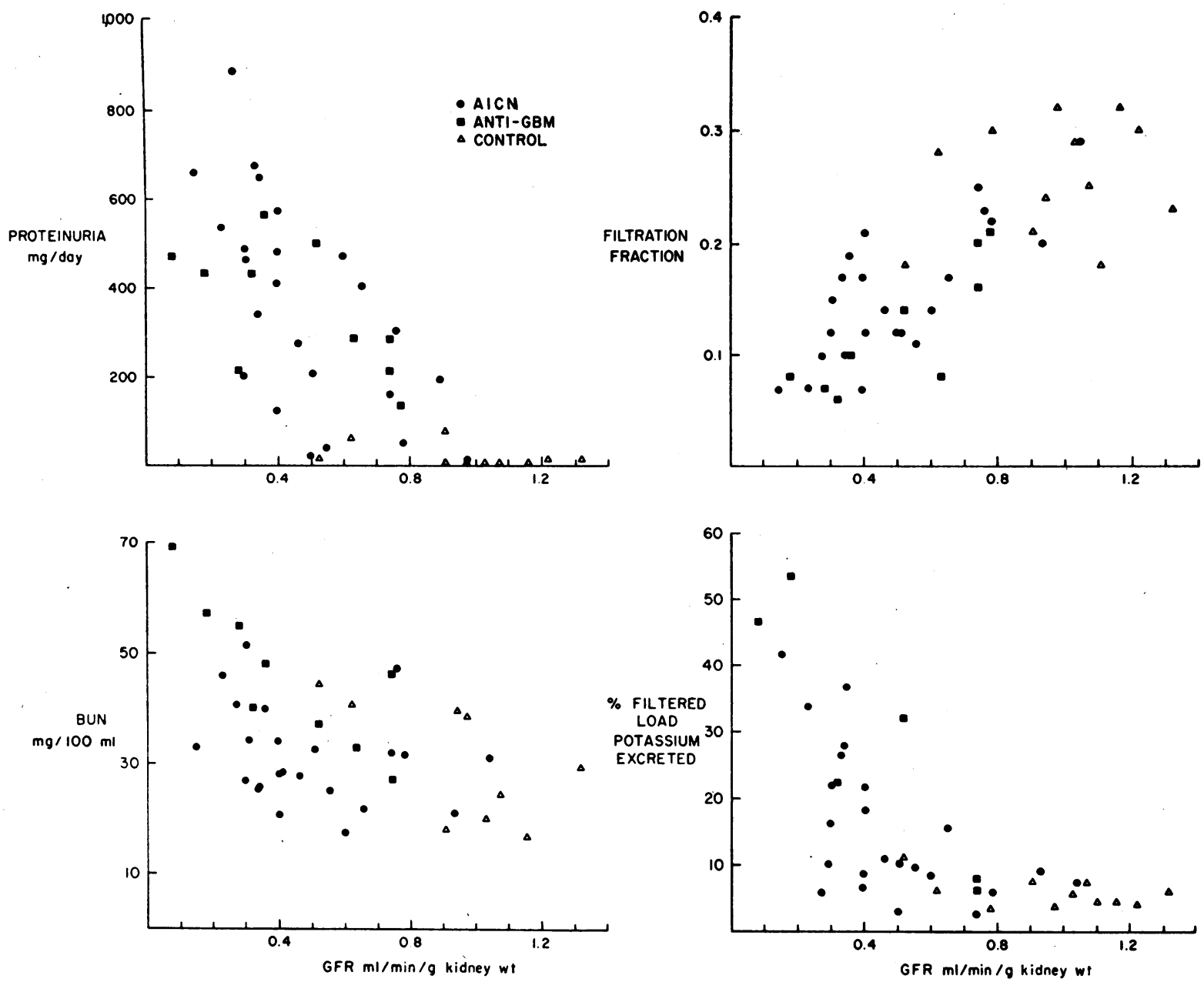

FIGURE 2 Relationship between the filtration rate of the left kidney and the degree of proteinuria, BUN concentration, FF, and fractional potassium excretion in 24 rats with AICN, 10 rats with anti-GBM nephritis, and in 12 controls.

$29.8 \mathrm{mg} / 100 \mathrm{ml} \pm 10.0 \mathrm{SD}$; anti-GBM $27-69 \mathrm{mg} / 100$ $\mathrm{ml}$, mean $44.3 \mathrm{mg} / 100 \mathrm{ml} \pm 13.4 \mathrm{SD}, P<0.001)$. Both experimental groups had significantly increased mean systemic blood pressure (controls : $106 \mathrm{~mm} \mathrm{Hg} \pm 11 \mathrm{SD}$, AICN : $118 \mathrm{~mm} \mathrm{Hg} \pm 14 \mathrm{SD}, P<0.02$; anti-GBM: $126 \mathrm{~mm} \mathrm{Hg} \pm 14, P<0.01)$.

\section{Clearance studies}

Clearance data are given for the (L) kidney, there being no statistically significant difference between the (R) and (L) kidney GFR.

Fig. 2 illustrates the relationship between kidney filtration rate and the degree of proteinuria, BUN concentration, FF, and potassium excretion. Quantitative proteinuria increased as the GFR fell (AICN: $r=$ $0.636, n=24, P<0.01$; anti-GBM : $r=0.869, n=10$, $P<0.01$ ). Filtration fraction fell in direct proportion to the fall in GFR, since the RPF, as measured by the clearance ( $\mathrm{C}_{\mathrm{PAB}}$ ) and extraction of PAH (E $\mathrm{E}_{\mathrm{PAB}}$ ) or inulin, did not decrease. Fractional excretion of sodium (not illustrated) and potassium increased, so that when the GFR was reduced to approximately $10 \%$ of control over $0.3 \%$ of the filtered load of sodium and $50 \%$ of the filtered load of potassium was excreted.

Table II compares the clearance data in animals with proteinuria in excess of $200 \mathrm{mg}$ per day with controls. GFR and RPF have been expressed in $\mathrm{ml} / \mathrm{min}$, $\mathrm{ml} / \mathrm{min} / \mathrm{g}$ kidney wt and $\mathrm{ml} / \mathrm{min} / 100 \mathrm{~g}$ body wt since kidney and body wt varied significantly between the anti-GBM rats and the others (Table III). Mean GFR was significantly reduced in both experimental models irrespective of the method of presentation. RPF, however, was significantly increased in the group with anti-GBM nephritis when calculated /100 $\mathrm{g}$ body wt. 
TABLE II

Clearance Data (Left Kidney) in Control Rats and in Glomerulonephritic Rats with Proteinuria Greater than $200 \mathrm{mg}$ per Day (Mean $\pm S D$ )

\begin{tabular}{|c|c|c|c|c|c|}
\hline & $\begin{array}{l}\text { AICN } \\
n=17\end{array}$ & $P$ & $\begin{array}{l}\text { Control } \\
n=12\end{array}$ & $P$ & $\begin{array}{c}\text { Anti-GBM } \\
n=9\end{array}$ \\
\hline \multicolumn{6}{|l|}{ GFR } \\
\hline$m l / \min$ & $1.04 \pm 0.4$ & $<0.001$ & $1.96 \pm 0.5$ & $<0.001$ & $0.71 \pm 0.36$ \\
\hline $\mathrm{ml} / \mathrm{min} / \mathrm{g}$ kidney wt & $0.40 \pm 0.16$ & $<0.001$ & $0.97 \pm 0.24$ & $<0.001$ & $0.43 \pm 0.24$ \\
\hline $\mathrm{ml} / \mathrm{min} / 100 \mathrm{~g}$ body $w t$ & $0.16 \pm 0.06$ & $<0.001$ & $0.30 \pm 0.08$ & $<0.001$ & $0.16 \pm 0.10$ \\
\hline \multicolumn{6}{|l|}{ RPF } \\
\hline $\mathrm{ml} / \mathrm{min}$ & $9.18 \pm 4.1$ & NS & $7.97 \pm 2.7$ & NS & $7.42 \pm 1.8$ \\
\hline $\mathrm{ml} / \mathrm{min} / \mathrm{g}$ kidney $w t$ & $3.39 \pm 1.29$ & NS & $3.94 \pm 1.31$ & NS & $4.70 \pm 1.44$ \\
\hline $\mathrm{ml} / \mathrm{min} / 100 \mathrm{~g}$ body $w t$ & $1.37 \pm 0.55$ & NS & $1.23 \pm 0.41$ & $<0.001$ & $2.47 \pm 0.74$ \\
\hline $\mathrm{FF}$ & $0.14 \pm 0.05$ & $<0.001$ & $0.27 \pm 0.05$ & $<0.001$ & $0.11 \pm 0.05$ \\
\hline $\mathrm{C}_{\mathrm{PAH}}{ }^{*}$ & $5.17 \pm 1.6$ & NS & $6.56 \pm 2.17$ & NS & $6.10 \pm 1.5$ \\
\hline $\mathrm{ml} / \mathrm{min} / \mathrm{g}$ kidney wt & $1.95 \pm 0.68$ & $<0.02$ & $3.22 \pm 0.89$ & NS & $3.88 \pm 1.29$ \\
\hline $\mathrm{ml} / \mathrm{min} / 100 \mathrm{~g}$ body $w t$ & $0.78 \pm 0.22$ & NS & $1.03 \pm 0.30$ & $<0.01$ & $2.03 \pm 0.62$ \\
\hline $\mathrm{C}_{\text {In }} / \mathrm{C}_{\mathrm{PAB}}$ & $0.18 \pm 0.03$ & $<0.01$ & $0.29 \pm 0.07$ & $<0.01$ & $0.14 \pm 0.06$ \\
\hline $\mathrm{E}_{\mathrm{PAH}}$ & $0.71 \pm 0.14$ & $<0.05$ & $0.86 \pm 0.06$ & NS & $0.83 \pm 0.08$ \\
\hline $\mathrm{U} / \mathrm{P}$ inulin & $194 \pm 131$ & $<0.001$ & $624 \pm 133$ & $<0.001$ & $225 \pm 142$ \\
\hline \multirow{3}{*}{$\begin{array}{l}\text { Sodium excretion } \\
\mu e q / \min \\
\% \text { Filtered load } \mathrm{Na} \\
\quad \text { excreted }\end{array}$} & & & & & \\
\hline & $0.21 \pm 0.13$ & NS & $0.18 \pm 0.24$ & NS & $0.19 \pm 0.15$ \\
\hline & $0.14 \pm 0.09$ & $\gtrless 0.05$ & $0.06 \pm 0.07$ & $<0.01$ & $0.19 \pm 0.09$ \\
\hline \multirow{3}{*}{$\begin{array}{l}\text { Potassium excretion } \\
\mu e q / \min \\
\% \text { Filtered load } \mathrm{K} \\
\text { excreted }\end{array}$} & & & & & \\
\hline & $1.08 \pm 0.65$ & NS & $1.01 \pm 0.90$ & NS & $0: 83 \pm 0.46$ \\
\hline & $18.6 \pm 11.8$ & $<0.01$ & $5.88 \pm 2.2$ & $<0.001$ & $29.5 \pm 18.3$ \\
\hline
\end{tabular}

$P$, comparison of control and AICN or anti-GBM data by unpaired Student $t$ test.

* $\mathrm{C}_{\mathrm{PAB}}$ was measured in eight AICN, six control, and seven anti-GBM rats.

Mean E $_{\mathbf{P A B}}$ was within normal limits (40) in anti-GBM nephritis while this was significantly reduced in the AICN rats. Electrolyte excretion rates and serum electrolyte concentrations were not significantly different in the three groups.

\section{Micropuncture studies}

Severely damaged kidneys from rats with either AICN or anti-GBM nephritis were enlarged, pale, and granular. Microscopic examination of the cortical surface of the living kidney showed marked heterogeneity of single nephron structure, the severity of which correlated generally with the severity of disease as judged by the whole kidney filtration rate. Patches of large, dilated, paler proximal tubules alternated with smaller areas of small atrophic-looking nephrons. White specks sometimes visible on the kidney surface were found to be tubular casts in dilated nephrons. Small whitish

TABLE III

Body Wt and Left Kidney Wt in Glomerulonephritic Rats and in Control Wistar Rats of Similar Age

\begin{tabular}{|c|c|c|c|c|c|c|c|c|}
\hline . & $\begin{array}{l}\text { Control } \\
n=12\end{array}$ & $\begin{array}{c}\text { AICN } \\
\text { Proteinuria } \\
200 \text { mg/day } \\
n=7\end{array}$ & $P$ & $\begin{array}{c}\text { AICN } \\
\text { Proteinuria } \\
200 \mathrm{mg} / \text { day } \\
n=17\end{array}$ & $P$ & $\begin{array}{l}\text { Control* } \\
n=20\end{array}$ & $\begin{array}{c}\text { Anti-GBM } \\
n=10\end{array}$ & $P$ \\
\hline Body wt & 649 & 634 & NS & 656 & NS & 326 & 290 & NS \\
\hline $\begin{array}{l}g \\
\text { Left kidney wt } \\
g / 100 \mathrm{~g} \text { body } w t\end{array}$ & $\begin{array}{c} \pm 61 \\
0.320 \\
\pm 0.04\end{array}$ & $\begin{array}{l} \pm 71 \\
0.333 \\
\pm 0.04\end{array}$ & NS & $\begin{array}{l} \pm 92 \\
\quad 0.406 \\
\pm 0.05\end{array}$ & $<0.001$ & $\begin{array}{l} \pm 46 \\
\quad 0.3803 \\
\pm 0.05\end{array}$ & $\begin{array}{c} \pm 51 \\
\quad 0.594 \\
\pm 0.17\end{array}$ & $<0.001$ \\
\hline
\end{tabular}

* Data obtained from Dr. R. Kramp. 
AICN
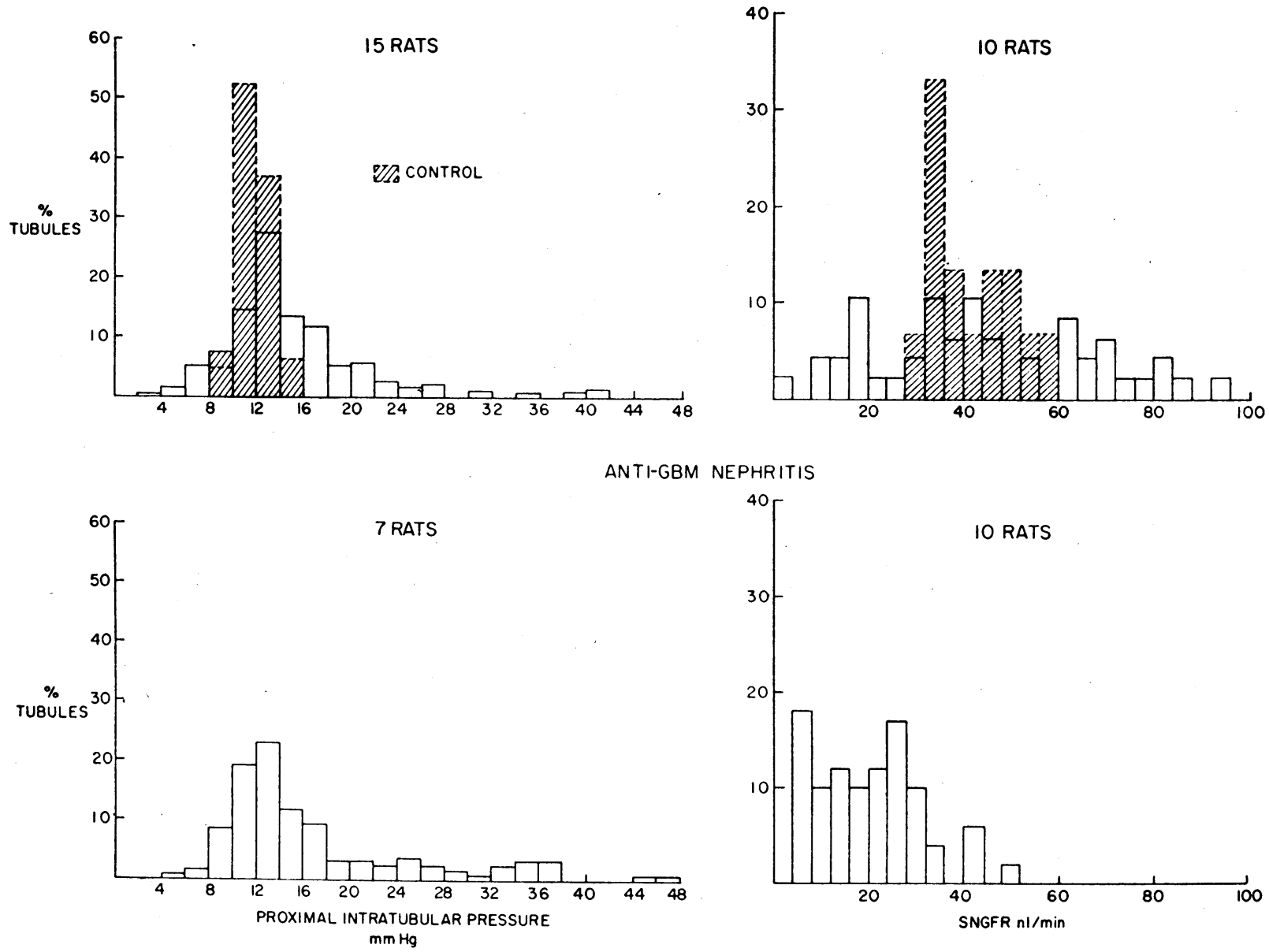

FIGURE 3 Distribution of proximal intratubular hydrostatic pressure and SNGFR measurements in 15 rats with AICN, eight rats with anti-GBM nephritis, and in controls.

pieces of material could at times be seen passing down tubules or adhering to the walls. The postglomerular circulation appeared less plentiful, with fewer "stars" and smaller peritubular capillaries. Less severely damaged kidneys, in animals with proteinuria less than 200 mg per day, showed only occasional patches of dilated nephrons and a normal looking post-glomerular vasculature.

Impressive functional heterogeneity was revealed by single nephron studies of filtration rate and proximal tubular hydrostatic pressure in both AICN and antiGBM rats with proteinuria over $200 \mathrm{mg}$ per day (Fig. $3)$. Thus in rats with AICN, SNGFR varied overall from 0 to almost $100 \mathrm{nl} / \mathrm{min}$. More importantly this pattern of functional heterogeneity was also found in individual kidneys. Although the mean SNGFR was significantly lower in the smaller rats with anti-GBM disease individual filtration rates again varied greatly, ranging from 0 to $50 \mathrm{nl} / \mathrm{min}$. These findings are to be compared with the much smaller scatter found in control rats, in which over $50 \%$ of all nephrons had filtration rates between 32 and $40 \mathrm{nl} / \mathrm{min}$.

Similarly proximal tubular hydrostatic pressure varied from 4 to $44 \mathrm{~mm} \mathrm{Hg}$ in AICN and from 4 to $48 \mathrm{~mm} \mathrm{Hg}$ in anti-GBM disease. In general those nephrons with high intratubular pressures appeared large and dilated on microscopic examination of the living kidney. In contrast, in control rats, all pressures recorded were between 8 and $16 \mathrm{~mm} \mathrm{Hg}$. We have previously shown (27) that proximal intratubular pressure is the same in normal rats weighing $230-275 \mathrm{~g}$ and $545-740 \mathrm{~g}$, similar to the weights of the anti-GBM and AICN rats, respectively.

Despite this marked heterogeneity of single nephron filtration rate absolute reabsorption to the late proximal convolution was in direct proportion to the filtra- 
tion rate, so that fractional reabsorption was uniform (Fig. 4). Thus in both forms of glomerulonephritis individual nephrons demonstrated almost complete proximal glomerulotubular balance at all levels of SNGFR.

Simultaneous measurements of SNGFR and whole kidney filtration rate were made in 52 nephrons in 11 animals with AICN, in 50 nephrons of 10 rats with anti-GBM nephritis, and in 15 nephrons of four control rats (Table IV). It is interesting to note that, although the mean whole kidney glomerular filtration rate was significantly reduced below control levels in the animals

TABLE IV

Comparison of Left Kidney Filtration Rate and mean SNGFR/ Kidney in Control and Glomerulonephritic Rats

\begin{tabular}{|c|c|c|}
\hline Group & $\begin{array}{c}\text { Whole } \\
\text { kidney } \\
\text { GFR }\end{array}$ & SNGFR \\
\hline & $m l / \min$ & $n l / \min$ \\
\hline \multirow[t]{11}{*}{$\mathrm{AICN}$} & 0.88 & 39.6 \\
\hline & 0.86 & 36.0 \\
\hline & 1.78 & 63.1 \\
\hline & 1.10 & 29.5 \\
\hline & 1.27 & 54.5 \\
\hline & 1.24 & 52.1 \\
\hline & 1.61 & 64.2 \\
\hline & 0.63 & 40.7 \\
\hline & 0.91 & 42.4 \\
\hline & 0.84 & 28.4 \\
\hline & 1.04 & 46.2 \\
\hline Mean & 1.11 & 43.3 \\
\hline SD & \pm 0.35 & \pm 12.6 \\
\hline$P$ & $<0.05$ & NS \\
\hline \multirow[t]{4}{*}{ Control } & 1.42 & 43.8 \\
\hline & 1.42 & 34.1 \\
\hline & 2.07 & 47.1 \\
\hline & 1.50 & 37.2 \\
\hline Mean & 1.60 & 40.6 \\
\hline SD & \pm 0.31 & \pm 6.0 \\
\hline \multirow[t]{10}{*}{ Anti-GBM } & 0.80 & 20.2 \\
\hline & 0.35 & 12.6 \\
\hline & 1.13 & 32.4 \\
\hline & 0.23 & 6.4 \\
\hline & 0.57 & 17.0 \\
\hline & 1.02 & 21.7 \\
\hline & 0.70 & 17.6 \\
\hline & 1.10 & 31.2 \\
\hline & 0.70 & 24.1 \\
\hline & 0.32 & 11.1 \\
\hline Mean & 0.69 & 19.4 \\
\hline $\mathrm{SD}$ & \pm 0.33 & \pm 8.4 \\
\hline$P$ & $<0.001$ & $<0.001$ \\
\hline
\end{tabular}

$P$, comparison of GFR and SNGFR data by unpaired Student $t$ test.

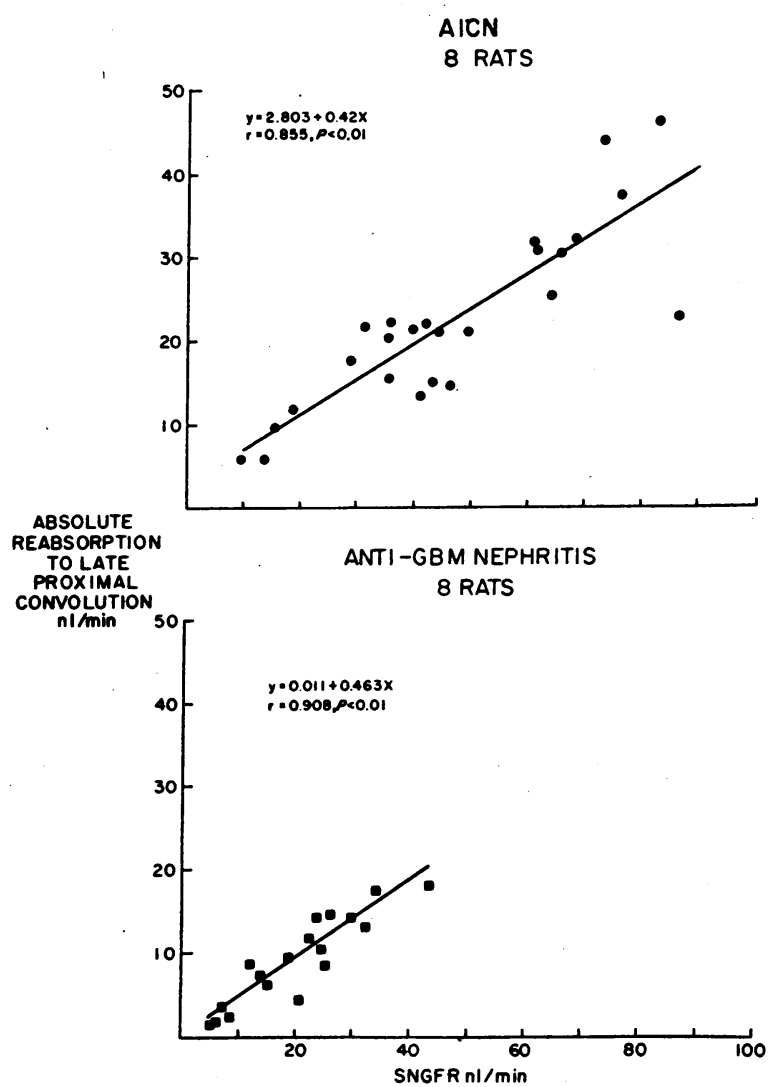

FIGURE 4 Correlation between absolute reabsorptive rate to the late proximal convolution and SNGFR in superficial nephrons of kidneys of rats with AICN and antiGBM disease.

with AICN, mean SNGFR was not different from controls. This could be due either to a sampling error in the selection of remaining nephrons for puncture in the sick rats, with a tendency to choose the more normal looking ones with the higher filtration rates, or to a fall in the whole kidney filtration rate in AICN resulting from the loss of substantial numbers of nephrons. We do not think that there was a major sampling error, since there was a good correlation between the mean SNGFR per rat and the whole kidney filtration rate (Fig. 5A). For any given level of whole kidney filtration rate, however, a wide range of SNGFR was found (Fig. 5B). Thus while the overall number of surviving nephrons was reduced those remaining were heterogeneous in function. In anti-GBM nephritis whole kidney and single nephron filtration rates were reduced to a similar degree, probably due to the acuteness and uniformity of the injury, suggesting that loss of more damaged nephrons had not yet occurred.

There was no significant difference between the mean values found for SNGFR, F/P inulin, and absolute re- 

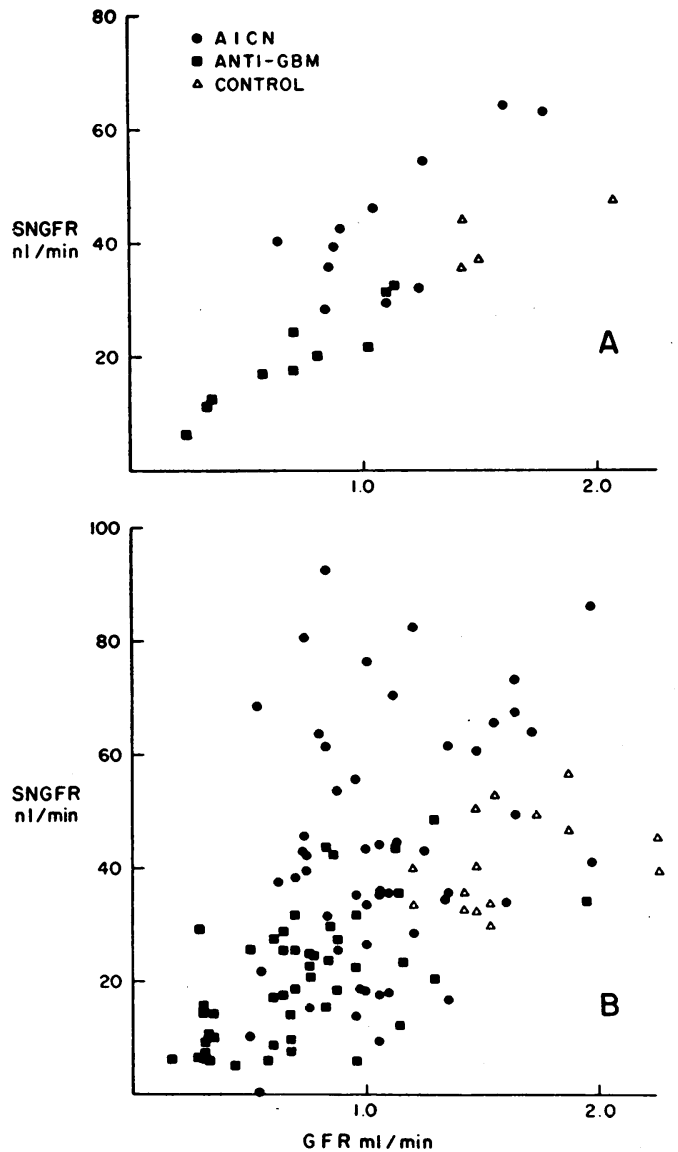

Figure 5 (A) Relationship of mean SNGFR per rat to whole kidney filtration rate in 11 rats with AICN, 10 with anti-GBM nephritis and in controls. (B) Relationship of individual SNGFR measurements to whole kidney filtration rate in the same rats.

absorptive rate to the late proximal convolution in the $\mathrm{AICN}$ and control rats (control $\mathrm{SNGFR}=41.7 \mathrm{nl}$ / $\min \pm 7.2 \mathrm{SD}, \mathrm{F} / \mathrm{P}$ inulin $=2.71 \pm 0.8 \mathrm{SD} ; \mathrm{AICN}$ $\mathrm{SN} . G F R=47.8 \mathrm{nl} / \mathrm{min} \pm 18.5 \mathrm{SD}, \mathrm{F} / \mathrm{P}$ inulin $=2.04$ $\pm 0.4 \mathrm{SD}$ ). Animals with anti-GBM disease had significantly lower SNGFR and absolute reabsorptive rates than either AICN or controls (SNGFR $=17.7 \mathrm{ml}$ / $\min \pm 8.6 \mathrm{SD}, \cdot \mathrm{F} / \mathrm{P}$ inulin $=1.81 \pm 0.2 \mathrm{SD}$ ), a finding not entirely explained by their smaller size since previous studies have shown the normal hydropenic Wistar rat kidney to have superficial SNGFR values of 25-35 nl/min. Mean F/P inulin values were not significantly different, probably due to the small number of observations involved in the control group.

Table $\mathrm{V}$ gives the mean values, calculated per rat, for the hydrostatic pressure in the carotid artery, efferent arteriole, large peritubular capillary, and proximal tubule in rats with AICN and in controls, together with the carotid pressure and free flow proximal tubular pressure in rats with anti-GBM nephritis. The latter had significantly higher systemic and proximal tubular pressures than the other two groups. No statistically significant difference in efferent arteriolar or peritubular capillary pressures were seen in the control and AICN rats, although it should be noted that all mean postglomerular hydrostatic pressures were lower in the animals with AICN. This tendency was even more marked in individual severely damaged kidneys, where the lowest peritubular capillary pressure recorded was $4.5 \mathrm{~mm} \mathrm{Hg}$ (lowest control $7.5 \mathrm{~mm} \mathrm{Hg}$ ).

Mean values for estimated glomerular oncotic and hydrostatic pressures, calculated per rat, in 11 animals with AICN, five with anti-GBM nephritis and in five control rats are given in Table VI. Animals with antiGBM disease had significantly lower afferent and efferent oncotic pressures, but significantly higher calculated $\mathrm{Pg}$ than the controls. Filtration equilibrium apparently was not reached in any of the three groups, this being especially marked in the rats with anti-GBM nephritis, mean estimated efferent EFP being $25.1 \mathrm{~mm}$ $\mathrm{Hg}$.

In an attempt to determine the factors regulating single nephron filtration rate we examined the relation-

TABLE V

Hydrostatic Pressure (mm Hg) in Carotid Artery, Proximal Tubules, Efferent Arterioles, and Peritubular Capillaries in Control and Glomerulonephritic Rats (Mean $\pm S D$ )

\begin{tabular}{lcccrr}
\hline & AICN & $P$ & Control & $P$ & Anti-GBM \\
\hline Carotid artery & $119 \pm 11.3(15)^{*}$ & $<0.02$ & $106 \pm 11.5(9)$ & $<0.0025$ & $125 \pm 6.8(7)$ \\
Efferent arteriole & $11.2 \pm 1.8(11)$ & $<0.05$ & $12.7 \pm 1.0(9)$ & - & - \\
Large peritubular capillary & $7.6 \pm 2.8(2)$ & NS & $10.3 \pm 2.0(5)$ & - & - \\
Proximal tubule & $13.1 \pm 5.4(15)$ & NS & $12.1 \pm 1.8(9)$ & $<0.0025$ & $16.2 \pm 2.9(7)$ \\
\hline
\end{tabular}

$P$, comparison of means by unpaired Student $t$ test.

* Figures in brackets refer to number of rats. 
ship between each nephron's measured filtration rate and intratubular hydrostatic pressure, calculated $\mathrm{Pg}$ and afferent and efferent EFP for that nephron. Fig. 6 shows the relationship between SNGFR and free flow hydrostatic pressure. In animals with AICN nephrons with higher intratubular pressures had low filtration rates. However in most instances no relationship was observed between SNGFR and pressure, a fivefold difference in SNGFR being found in nephrons of similar intratubular pressure. In the anti-GBM group a threefold difference in intratubular pressure was not associated with any difference in filtration rate.

A closer relationship was seen between single nephron filtration rate and calculated Pg (Fig. 7), the relationship being statistically significant, however, only for the rats with anti-GBM disease. It is interesting to note that although the mean calculated capillary pressure was almost the same in the two groups (55.3 $\mathrm{mm} \mathrm{Hg}$ in $\mathrm{AICN}$ and $58.0 \mathrm{~mm} \mathrm{Hg}$ in anti-GBM) mean SNGFR was significantly greater in the AICN group $(37.0 \mathrm{nl} / \mathrm{min}$ in AICN, $21.6 \mathrm{nl} / \mathrm{min}$ in antiGBM) suggesting, perhaps, a difference in glomerular membrane filtration characteristics in the two disease states, as in permeability and/or area.

SNGFR was also closely related to calculated afferent and efferent EFP (Fig. 7). Filtration equilibrium was apparently approached only in those nephrons with very low filtration rates and the higher free flow pressures. Nephrons with higher filtration rates did not appear to reach equilibrium, estimated efferent EFP being as high as 45-65 $\mathrm{mm} \mathrm{Hg}$.

\section{Microinjection studies}

Structural and functional changes in the kidneys of the animals used for microinjection studies were similar to those previously described. Proteinuria ranged from 133 to $550 \mathrm{mg}$ per day (mean $305 \mathrm{mg} \pm 123 \mathrm{SD}$ ) and BUN from 14 to $116 \mathrm{mg} / 100 \mathrm{ml}$ (mean $44.8 \mathrm{mg}$ / $100 \mathrm{ml} \pm 36.4 \mathrm{SD}$ ). Two animals developed gross ascites and edema with serum protein concentrations of 1.9 and $1.8 \mathrm{mg} / 100 \mathrm{ml}$.

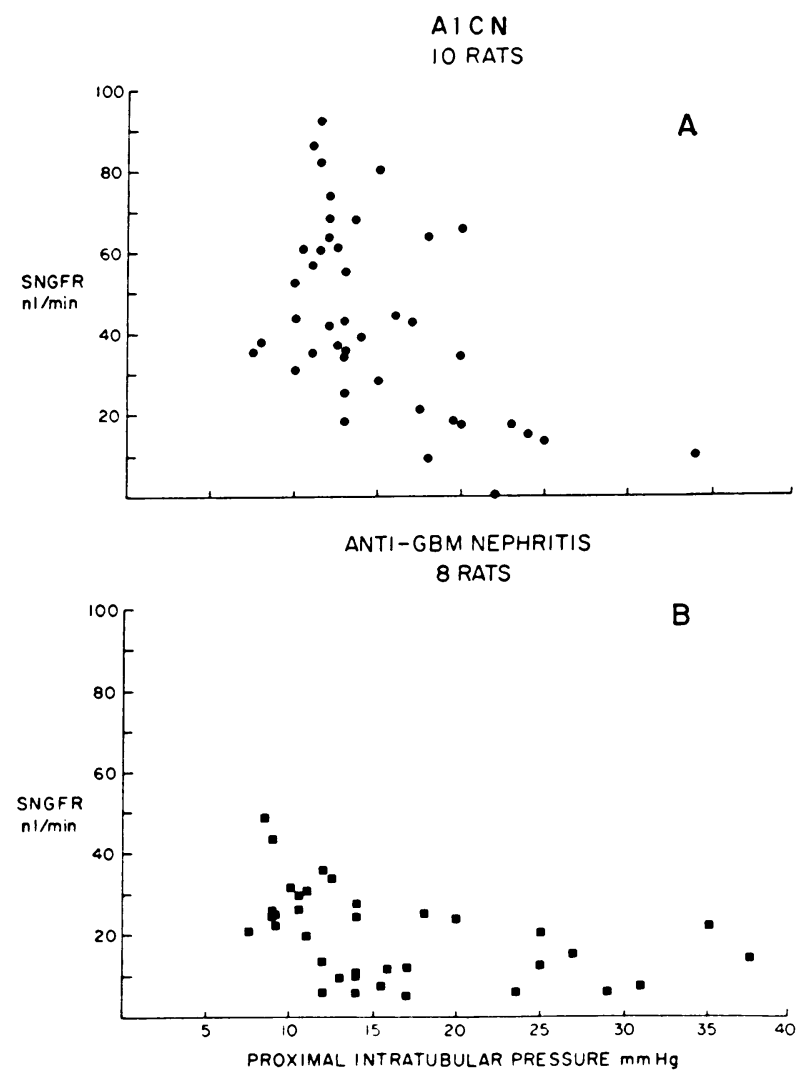

FIGURE 6 Relationship of SNGFR to proximal intratubular free flow hydrostatic pressure in (A) rats with AICN and in (B) rats with anti-GBM disease.

No evidence of significant leakage of inulin was found in those nephrons which appeared normal in vivo and in which the intratubular hydrostatic pressure was less than $19 \mathrm{~mm} \mathrm{Hg}$. In 26 microinjected proximal tubules (20 anti-GBM, 6 AICN) hydrostatic pressure averaged $13.0 \mathrm{~mm} \mathrm{Hg} \pm 2.7 \mathrm{SD}$ and inulin recovery from the injected kidneys averaged $98.2 \% \pm 9.1 \mathrm{SD}$. The latter is not different from the average value of 98.4 $\pm 2.6 \mathrm{SD}$ found in seven control tubules. There was no

TABLE VI

Calculated Glomerular Capillary Hydrostatic and Oncotic Pressures ( $\mathrm{mm} \mathrm{Hg}$ ) in Control and Glomerulonephritic Rats (Mean $\pm S D)$

\begin{tabular}{lccccc}
\hline & $\begin{array}{c}\text { AICN } \\
n=11\end{array}$ & $P$ & $\begin{array}{c}\text { Control } \\
n=5\end{array}$ & $P$ & $\begin{array}{c}\text { Anti-GBM } \\
n=5\end{array}$ \\
\hline Afferent oncotic pressure & $16.1 \pm 1.04$ & NS & $15.4 \pm 0.96$ & $<0.02$ & $13.8 \pm 0.67$ \\
FF & $0.14 \pm 0.02$ & $<0.001$ & $0.22 \pm 0.02$ & $<0.001$ & $0.12 \pm 0.01$ \\
Efferent oncotic pressure & $20.1 \pm 1.84$ & $<0.02$ & $22.9 \pm 2.2$ & $<0.001$ & $16.6 \pm 0.93$ \\
Pg & $55.9 \pm 7.4$ & $<0.02$ & $47.4 \pm 3.3$ & $<0.02$ & $58.5 \pm 9.4$ \\
Afferent EFP & $24.7 \pm 8.5$ & NS & $19.9 \pm 3.1$ & NS & $27.6 \pm 10.9$ \\
Efferent EFP & $20.3 \pm 8.7$ & $<0.1$ & $12.4 \pm 3.0$ & NS & $25.1 \pm 25.0$ \\
\hline
\end{tabular}



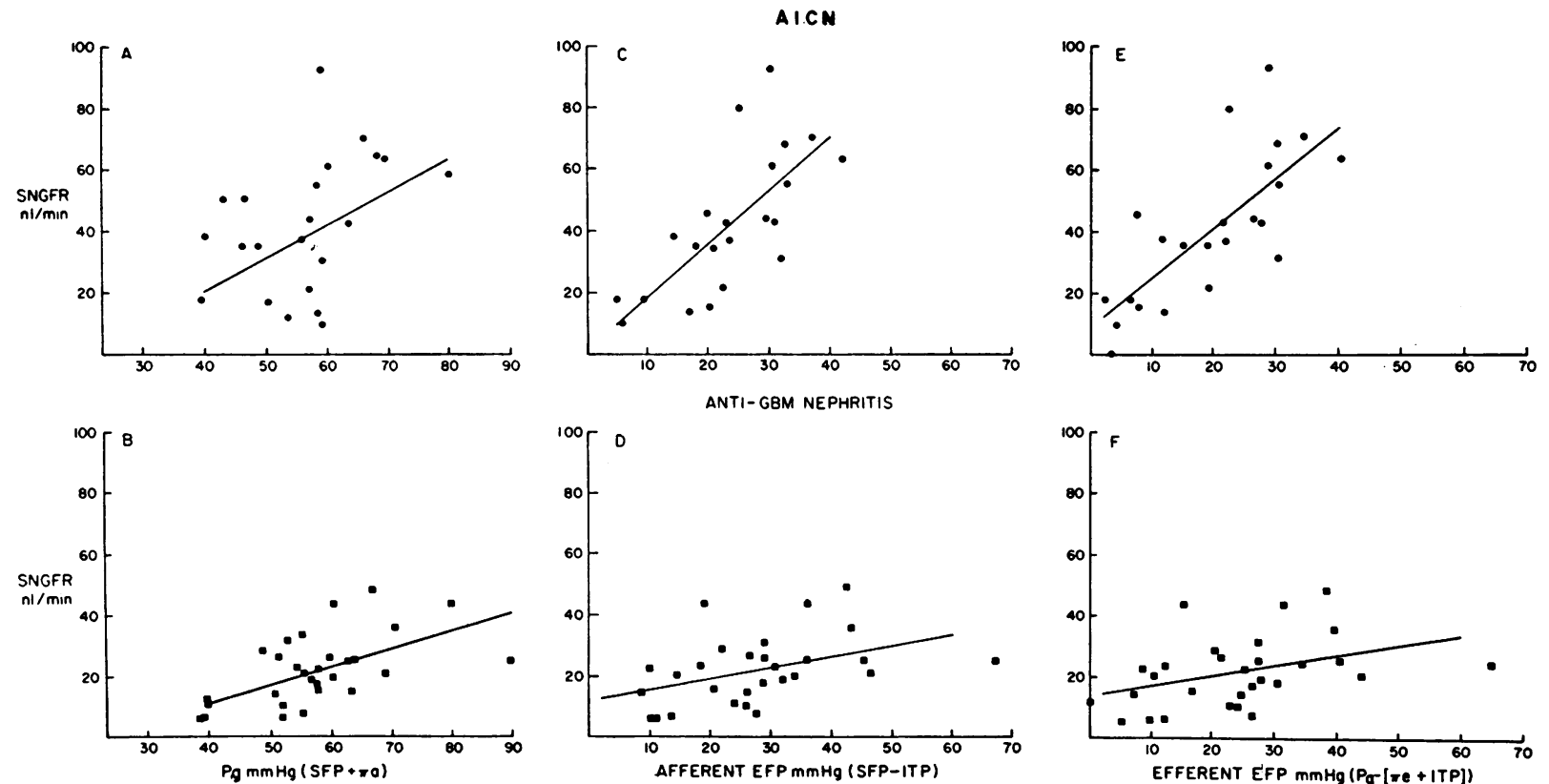

Figure 7 (A and B) Correlation between calculated Pg and SNGFR in AICN (A, $r=$ $0.362, P>0.05$ ) and in anti-GBM nephritis (B, $r=0.556, P<0.01$ ). (C and D) Correlation between calculated afferent EFP and SNGFR in AICN $(C, r=0.754, P<0.01)$ and antiGBM nephritis ( $D, r=0.453, P<0.01)$. (E and F) Correlation between calculated efferent EFP and SNGFR in AICN (E, $r=0.759, P<0.01$ ) and in anti-GBM nephritis $(F, r=$ $0.414, P<0.05)$. ITP, intratubular pressure; $\pi \mathrm{a}$, afferent oncotic pressure; $\pi$, efferent oncotic pressure; SFP, stop flow pressure.

statistically significant excretion of inulin by the right kidney. Urine flow rate averaged $13 \mu \mathrm{l} / \mathrm{min}$, and the injectate appeared in early distal tubules $0.8-4 \mathrm{~min}$ after proximal injection, except in one nephron where the flow rate was very slow, $25 \mathrm{~min}$ elapsing before the injectate reached the early distal segment.

The eight microinjected anti-GBM nephrons with higher intratubular pressures (mean $24.4 \mathrm{~mm} \mathrm{Hg} \pm 6.2$ SD) appeared dilated and all had very slow flow rates. In most the injectate remained visible in the superficial proximal tubule for 1-2 $\mathrm{h}$. In three no significant radioactivity was recovered from either kidney. In the other five, however, $19.8 \% \pm 4.3$ and $19.6 \pm 7.2$ of the microinjected inulin was recovered in the urine from the left and right kidneys, respectively. Although we are unable to exclude the possibility of a significant transtubular leakage of inulin in this circumstance, the leakage may well have occurred, in view of the high intratubular pressure and very slow tubular flow rate, at least in part, at the site of puncture and thus have no physiological significance.

\section{Immunopathologic studies}

Histologically, the renal lesions induced either by autologous immune complex deposits or by anti-GBM antibodies were quite characteristic as were the immunofluorescent findings. Varying severities of involvement were present in both models so that attempts to correlate physiologic and immunopathologic variations were possible.

$A I C N$. The glomerular lesions in the AICN rats developed slowly and were typified by uniform thickening of the glomerular basement membrane (GBM) with only minimal glomerular hypercellularity and increase in polymorphonuclear leukocytes characteristic of membranous glomerulonephritis. Proliferation of Bowman's capsule (crescent formation) and glomerular sclerosis were infrequent. The severity of glomerular involvement was quite uniform throughout the cortex of each individual kidney (Fig. 8). Although the GBM was obviously thickened in all rats studied in this group, the degree of thickening was extremely difficult to estimate even semi-quantitatively from PAS-stained sections and correlated poorly with the severity of either proteinuria $(r=0.105, n=23)$ or fall in GFR $(r=0.245, n=23)$ (Table VII).

These glomerular lesions were accompanied by changes in the renal tubules and interstitium which led to different degrees of derangement in overall renal architecture. This latter parameter, which, in addition 

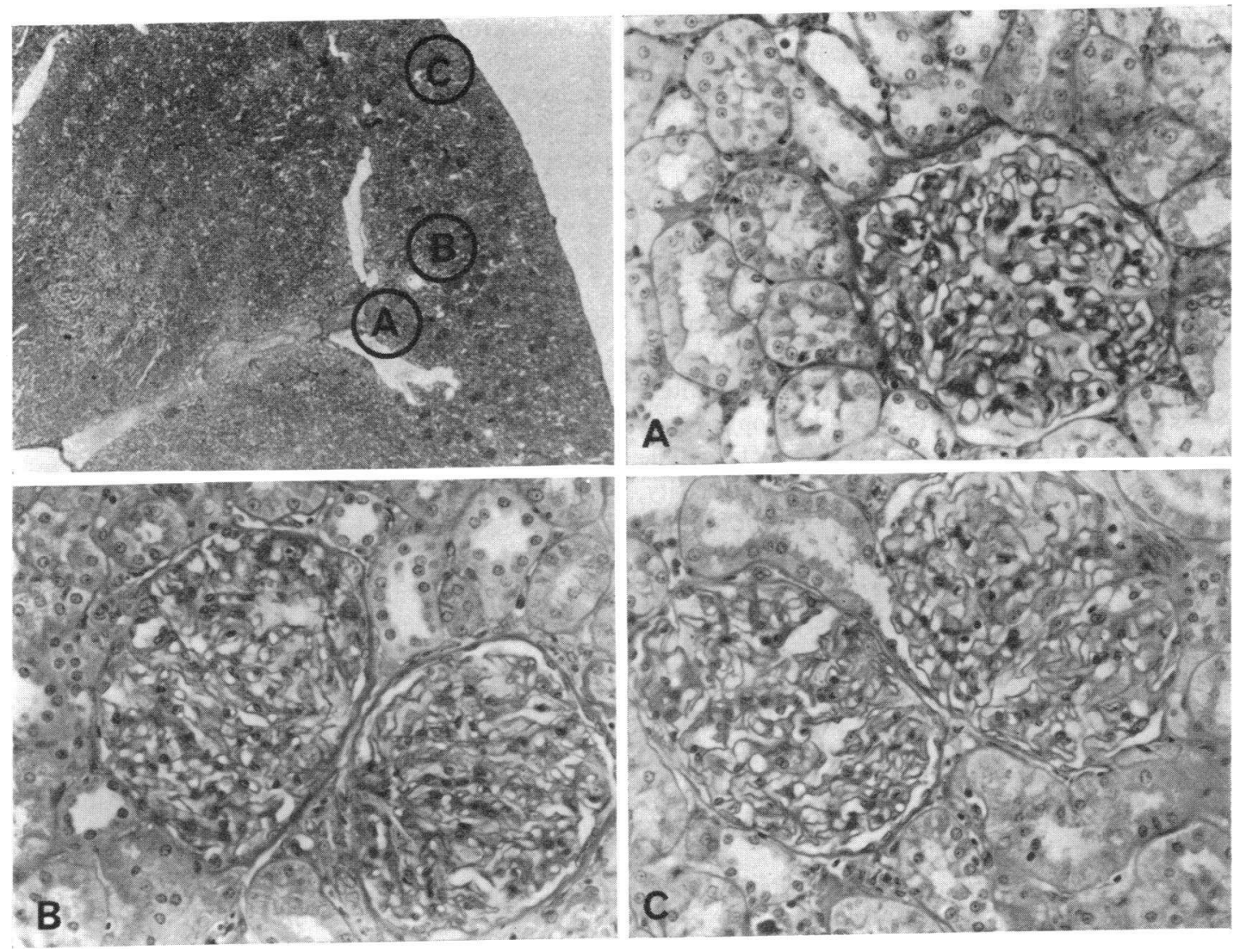

FIGURE 8 The uniformity of membranous thickening of the GBM is shown at different levels in the cortex from a rat with AICN. Virtually no proliferation accompanied the thickening of the GBM as seen in glomeruli near the arcuate vessels (A) in the mid-cortex (B) or in the superficial cortex (C). PAS stain. A-C, $\times 220$.

to the glomerular pathology, was comprised of varying degrees of tubular atrophy and dilatation, interstitial mononuclear cell infiltration, tubular casts, and the presence of intraluminal cells contining PAS-positive material either singly or in multinucleated form (Fig. 9), correlated directly with the fall in GFR $(r=0.747$, $n=23, P<0.01)$ as well as with proteinuria $(r=$ $0.711, n=23, P<0.01$ ) (Table VII). Similar correlations could be made when each component was analyzed separately. Surprisingly, for the degree of overall renal damage, only minimal medial thickening of small arterioles was observed in the most hypertensive rats.

Granular deposits of IgG and C3 were present diffusely along the GBM (Fig. 10) in the 23 AICN rats available from the 24 undergoing clearance studies. This deposition correlated poorly with amounts of proteinuria and only in a general way with GBM thickening assessed by light microscopy. The deposits were most clear in rats with less structural glomerular damage. As glomerular sclerosis developed, the deposition lessened in both intensity and extent. IgG eluted (36) from these kidneys reacted with antigens present in the brush border of normal proximal renal tubules when tested by indirect immunofluorescence on normal kidney sections.

Of additional interest, evidence from the immunofluorescent studies suggested an immune nature for some of the renal tubular lesions observed in these animals. IgG and C3 were found deposited along the brush border of $8 / 23$ of the more heavily proteinuric AICN rats studied (Fig. 11). This observation would suggest that antibodies specific for rat RTA (resident in the brush border) of the proximal convoluted tubule were being filtered and bound in vivo. This finding correlated well with the presence of chunks of IgG and $\mathrm{C} 3$ within the tubular lumens, unrelated to tubular casts, and the presence of cells containing PAS-positive material adjacent to the brush borders and free within the tubular lumens (Fig. 9). In addition to brush border and occasional intraluminal deposits of IgG and C3 (unrelated to albumin-containing casts) granular deposits of these immunoreactants were observed in 
the tubular cytoplasm near the TBM. This suggests that immune complexes either filtered into or formed in the tubular urine were being taken up by the tubular cells or that antibody had gained access to the cells to combine with intracellular antigens. Similar observations have been made in Sprague Dawley rats with AICN augmented by pertussis (41). No evidence of anti-TBM antibodies was found by immunofluorescence in this study.

Anti-GBM glomerulonephritis. In rats with experimental anti-GBM glomerulonephritis, the degree of GBM irregularity, crescent formation, and architectural derangement assessed by light microscopy correlated well with the fall in GFR (Table VII). The glomerular pathology typified by increased cellularity, polymorphonuclear leukocyte infiltration, proliferation of Bowman's capsule (crescent formation), and irregularly thickened GBM was accompanied by corresponding degrees of general architectural derangement including tubular atrophy and interstitial cellular infiltration. Glomerular alterations were quite uniform throughout the cortex (Fig. 12), possibly with a slightly greater hypercellularity in the more superficial glomeruli. Virtually no vascular changes were encountered, although the animals had significantly increased mean systemic blood pressure.

Immunofluorescent studies revealed similar intensities of linear IgG and C3 deposits in the nine kidneys available for study. In kidneys with more GBM damage, the linear IgG and C3 deposits were increasingly irregular (Fig. 10) corresponding to the loss of the normal smooth, ribbon-like structure of the GBM. The pattern of deposition, however, was always easily distinguishable from the granular immune complex deposits typifying the AICN rats. Virtually no IgG deposits were noted outside the glomeruli.

Controls. Seven of the control rats had minimal glomerular hypercellularity, irregularity of the GBM, and architectural derangement. These rats also had mild proteinuria and slight decreases in renal function. The histological and functional abnormalities correlated with advancing age but not with the administration of CFA. Spontaneous glomerulonephritis with advancing age has been described in Wistar rats (42). The remaining control rats were free of histologic or functional abnormalities.

Small amounts of IgG and/or C3 in a segmental granular pattern were found in glomeruli of the rats with histologic glomerular abnormalities suggesting the presence of a low-grade spontaneous immune complex glomerulonephritis as has been reported in many animal species. No attempts were made to identify the antigenic portion of the presumed immune complex in these animals. Similar IgG deposits were found in two additional rats that remained histologically and functionally normal.

TABLE VII

Relationship of Whole Kidney Function to Changes Seen on Light Microscopy of Right Kidney in Control and Glomerulonephritic Rats*

\begin{tabular}{|c|c|c|c|c|c|c|c|}
\hline Group & $\begin{array}{c}\text { Glomerular } \\
\text { hypercellularity }\end{array}$ & $\begin{array}{c}\text { GBM } \\
\text { thickening }\end{array}$ & Crescents & $\begin{array}{l}\text { Architectural } \\
\text { derangement }\end{array}$ & GFR & $\begin{array}{l}\mathrm{U} / \mathrm{P} \\
\text { Inulin }\end{array}$ & Proteinuria \\
\hline & & & $\%$ glomeruli & & $\begin{array}{l}m l / m i n g \\
k i d n e y \text { wt }\end{array}$ & & $m g / 24 h$ \\
\hline AICN & & & & & & & \\
\hline$n=11$ & 0.4 & 2.0 & $0-10$ & 1.7 & 0.30 & 122 & 535 \\
\hline$n=12$ & 0.5 & 1.8 & Rare & 0.9 & 0.74 & 350 & 205 \\
\hline \multicolumn{8}{|l|}{ Control } \\
\hline$n=7$ & 0.6 & 0.4 & 0 & 0.3 & $0.78 \S$ & $550 \S$ & 66 \\
\hline$n=10$ & 0.1 & 0 & 0 & 0 & $1.14 \|$ & $631 \|$ & 10 \\
\hline \multicolumn{8}{|l|}{ Anti-GBM } \\
\hline$n=5$ & 1.9 & $1.7 \pi$ & $10-70$ & 1.8 & 0.19 & 100 & 426 \\
\hline$n=5$ & 1.4 & $1.3 \pi$ & $0-5$ & 0.7 & 0.71 & 359 & 287 \\
\hline
\end{tabular}

All figures are means.

* Animals in each group have been subdivided on the basis of GFR. Mean glomerular hypercellularity, GBM thickening, and architectural derangement were calculated from individual animals graded on a $0-4+$ scale (see Methods) where $\pm=0.25$, trace $=0.5,1=1$, etc.

$\ddagger$ Includes gross glomerular changes, tubular atrophy and dilatation, interstitial mononuclear cell infiltration, casts, and intraluminal cells.

$\S$ Data from four rats.

II Data from nine rats.

II Irregularity and fraying.

1414 M. E. M. Allison, C. B. Wilson, and C. W. Gottschalk 

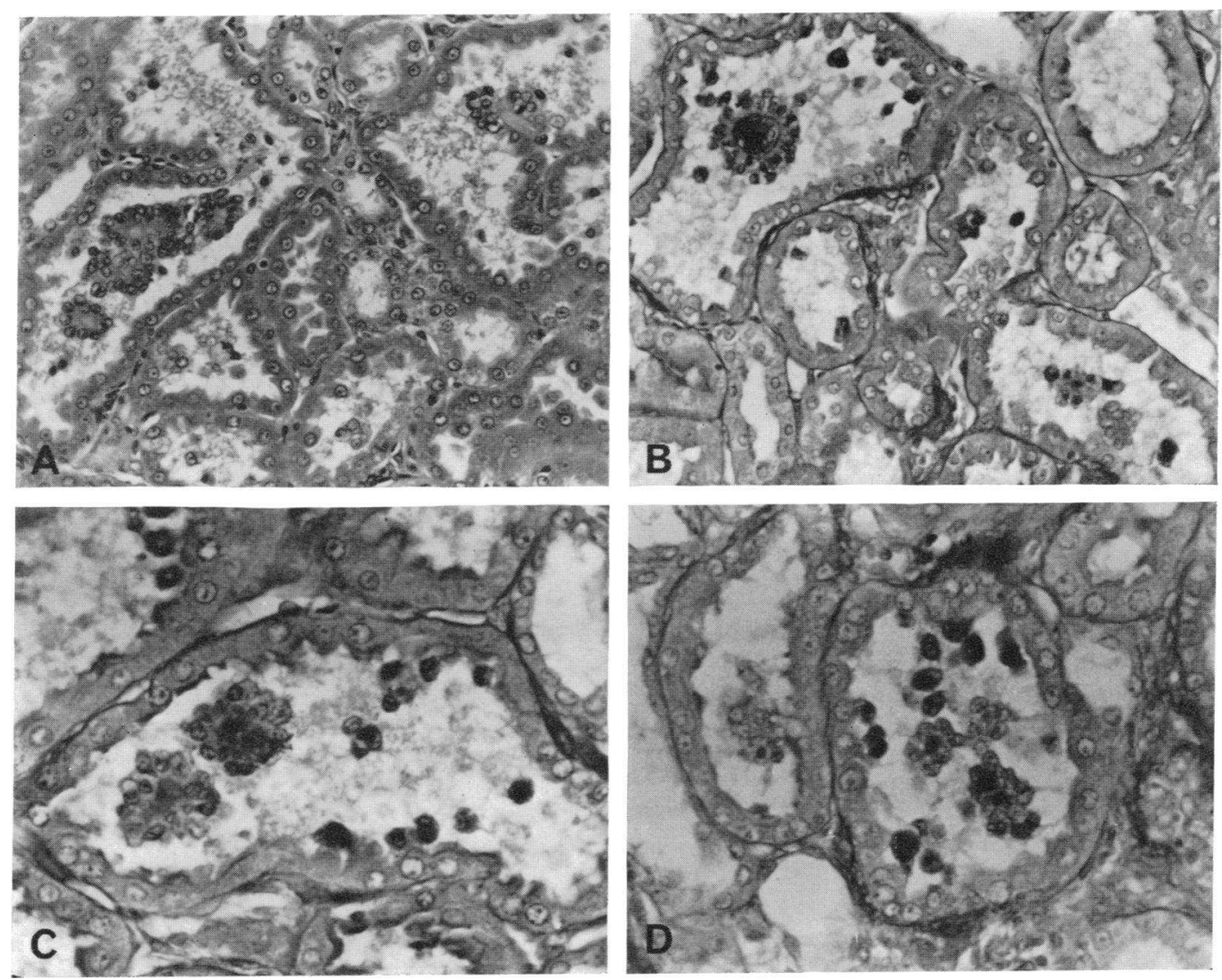

Figure 9 Accumulations of cells were noted in the lumens of tubules in the AICN rats. The PAS-positive brush border area of the tubular cells appeared to be stripped from segments of the lining epithelium and phagocytized by mononuclear cells which tended to become multinucleated. Mononuclear cell infiltrates were also noted adjacent to some renal tubules (D). Hematoxylin-eosin stain (A) and PAS stain (B-D) A and B, $\times 220$; C and D, $\times 350$.

\section{DISCUSSION}

This study was designed to measure single nephron function in histologically different experimental glomerulonephritides morphologically resembling human glomerulonephritis. Examples of the two major immunopathogenic mechanisms of glomerulonephritis were chosen. Firstly, AICN was used as a model of immune complex(nonglomerular antigen-antibody)-induced glomerular injury, a mechanism which appears to be responsible for approximately $80 \%$ of human glomerulonephritis (43). The RTA-antibody system which typifies AICN has recently been identified in three patients with membranous glomerulonephritis from Japan (44). Secondly, anti-GBM antibodies were used to induce glomerular injury typified by an acute onset (within hours) of a diffuse, proliferative glomerular lesion similar to the infrequently found (approximately 5\%) anti-GBM antibody-induced glomerulonephritis in man (36). It should be noted that, although AICN has the morphology of a membranous glomerulo- nephritis, immune complex glomerulonephritis can assume virtually any type of glomerulonephritic histologic alteration, apparently influenced more by the intensity and tempo of the immune reaction and the subsequent host response than by the inciting event. Both antibody-induced forms of glomerular injury utilize common mediation pathways, namely complement and polymorphonuclear leukocytes, so that observations made in this study dealing with diffuse proliferative glomerulonephritis induced by anti-GBM antibodies might also apply to similar morphologic lesions induced by immune complexes.

Measurement of whole kidney function in our glomerulonephritic rat models revealed changes very similar to those previously reported in extensive clinical studies of renal function in human glomerulonephritis. Thus whole kidney GFR and FF fell, RPF, determined by the clearance and extraction of $\mathrm{PAH}$, remaining unchanged in the more chronic AICN disease or increasing slightly in the acute, proliferative anti-GBM 

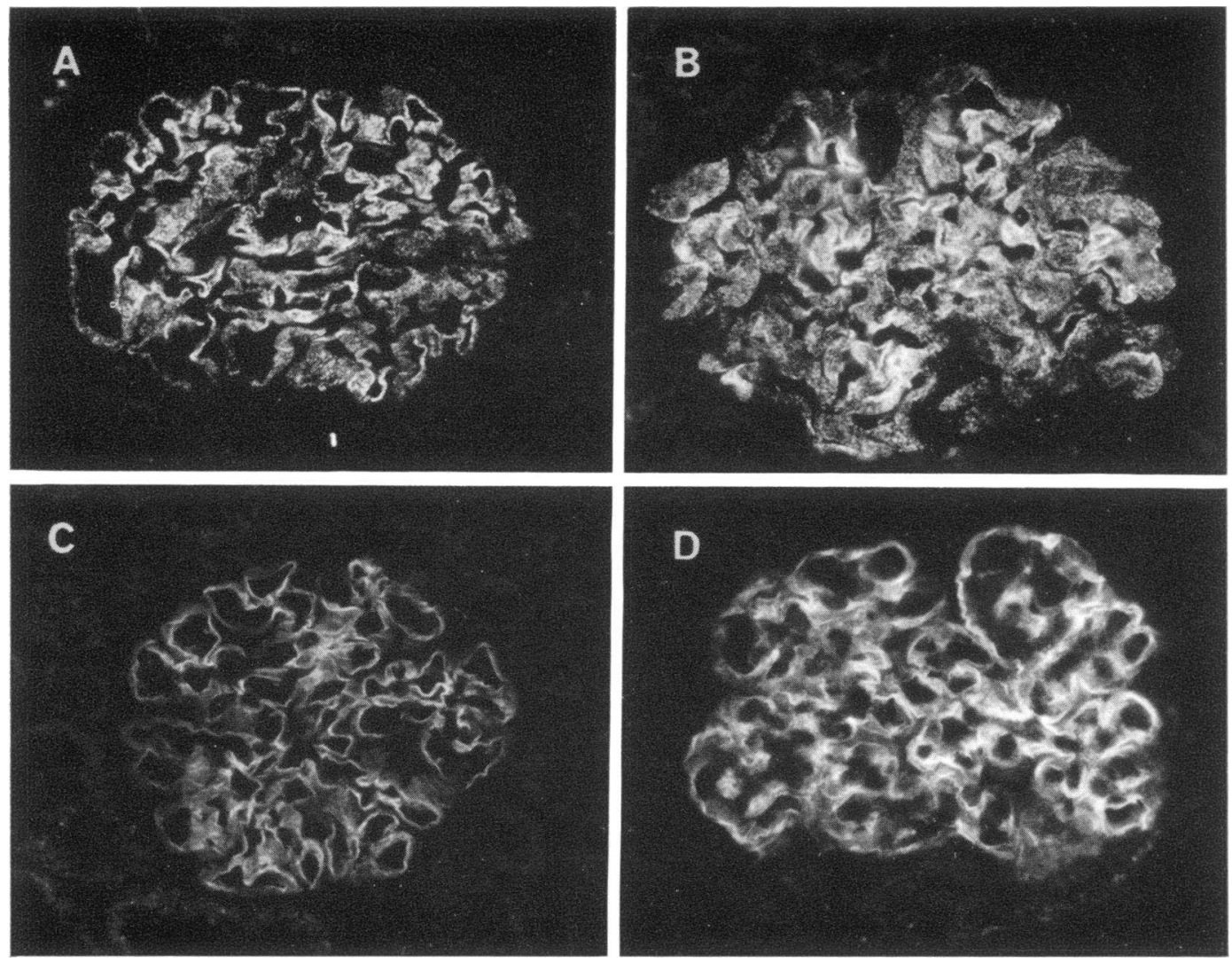

FIgURE 10 Granular deposits of immunoglobulin were observed in the glomeruli of the AICN rats. The fine granularity was present diffusely along the GBM where little thickening (A) or after extreme thickening (B) had occurred. Linear deposits of immunoglobulin typified the glomerulonephritis introduced by heterologous anti-GBM antibodies. (C) The pattern was very smooth and continuous in kidneys with well preserved glomerular architecture. (D) With greater degrees of glomerular damage, the immunoglobulin pattern became increasingly irregular with apparent fraying of the GBM. Fluorescein isothiocyanate-conjugated anti-rat IgG. $\times 250$.

nephritis. Such observations have been frequently reported in acute, subacute, and early chronic glomerulonephritis in humans $(1,2,45)$. Absolute electrolyte excretion rates were not significantly different from controls, but this was achieved by an increase in the fractional electrolyte excretion as the GFR fell, a necessary adaptive response previously documented in patient studies $(3,10,46)$. Only two of our rats developed edema or ascites, although this has been reported as often accompanying experimental immune complex and anti-GBM disease in rats $(18,47)$.

The most striking physiological feature in both models of experimental glomerulonephritis was the finding that each nephron studied showed almost complete glomerulotubular balance, despite marked heterogeneity of SNGFR, proximal free flow intratubular hydrostatic pressure, and calculated glomerular capillary pressure. It might be argued that the heterogeneity of
SNGFR could, in part, be due to a variable loss of inulin from structurally damaged nephrons. From our own and other observations, however, we do not believe that inulin leakage contributed substantially to our findings. No evidence of inulin leakage was found in nephrons with intratubular hydrostatic pressure less than $19 \mathrm{~mm} \mathrm{Hg}$, despite marked heterogeneity of SNGFR in such nephrons (Fig. 6). A significant loss of inulin was seen in only five nephrons with high intratubular pressure and very slow flow rates, three other nephrons with high pressure and slow flow showing no evidence of leakage after proximal microinjection. It is technically very difficult to exclude the possibility of a small but significant leakage of tubular fluid onto the surface of the kidney around the site of injection in nephrons with high intratubular pressure which might have caused, at least in part, the calculated inulin leakage. 

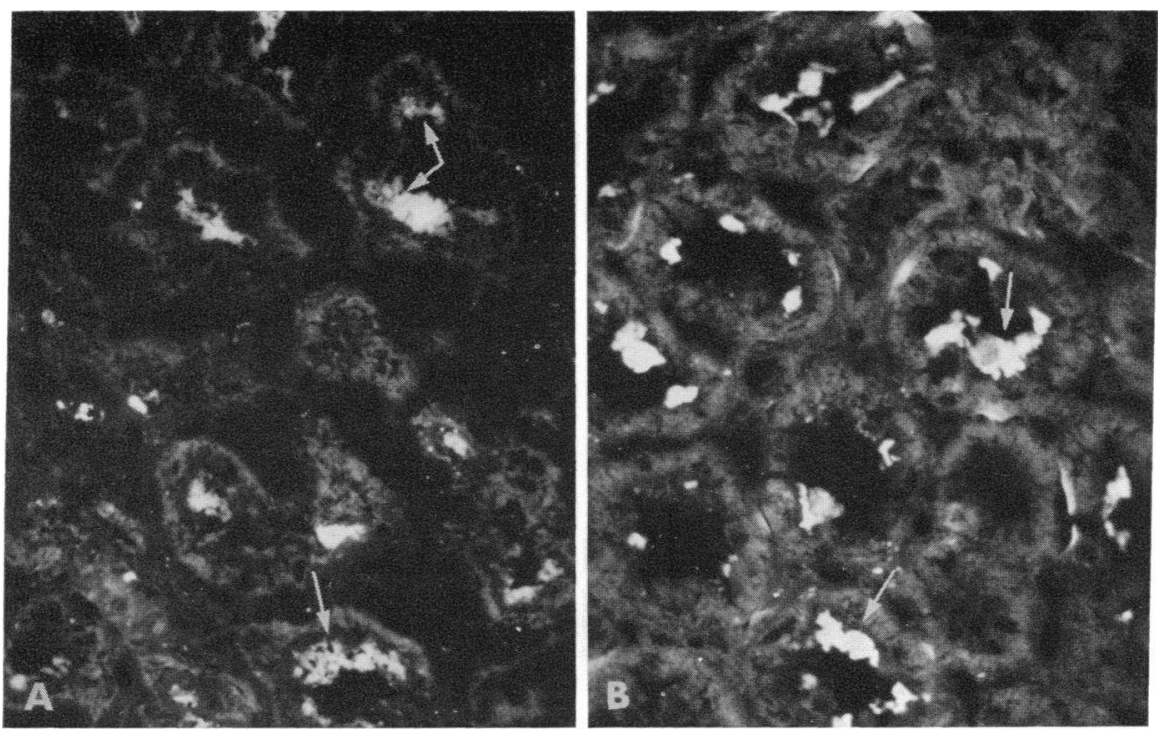

Figure 11 Heavy deposits of IgG (A) and C3 (B) were observed in the area of the brush burder (arrows) of foci or "islands" of renal tubular cells in some of the AICN rats with more extensive architectural abnormalities. Fluorescein isothiocyanate-conjugated anti-rat IgG (A) and C3 (B). $\times 250$.

Moreover, even if the calculated inulin leakage resulted from the transtubular movement of microinjected inulin, it does not necessarily follow that a similar fraction of inulin filtered in that nephron would leak. Fractional inulin leakage is a function of contact time and SNGFR would have to be vanishingly small, less than $0.3 \mathrm{nl} / \mathrm{min}$, for tubular transit time to be as long, circa $1 \mathrm{~h}$, as the observed contact time in these dilated and obstructed high pressure nephrons studied by microinjection. Accepting the average leakage observed in the five obstructed tubules and assuming a tubular diameter twice normal, one can calculate that less than $3 \%$ of filtered inulin would leak at an SNGFR of $5 \mathrm{nl} / \mathrm{min}$ and less than $1.5 \%$ at an SNGFR of 10 $\mathrm{nl} / \mathrm{min}$.

In addition, if transtubular inulin leakage at high intratubular pressure were a significant factor one might expect to find a correlation between SNGFR, late proximal F/P inulin level, and intratubular hydrostatic pressure, high pressure nephrons having lower SNGFR and $F / P$ inulin values. No such relationship was observed in anti-GBM nephritis, although in AICN rats mean SNGFR in high pressure nephrons was significantly lower $(26.0 \mathrm{nl} / \mathrm{min} \pm 22.4 \mathrm{SD})$ than that found in more normal pressure nephrons $(48.6 \mathrm{nl} / \mathrm{min}$ $\pm 19.9 \mathrm{SD}, P<0.005)$. Late proximal $\mathrm{F} / \mathrm{P}$ inulin ratios, however, were not significantly different. In a recent study of experimental glomerulonephritis produced by rabbit anti-rat kidney serum, a model presumably quite similar to our anti-GBM rats, Rocha, Marcondes, and Malnic (17) found that SNGFR was not different when calculated from proximal or distal samples and concluded that there was no evidence of inulin loss from the nephritic tubules. Lastly, microinjection studies in animal models with severe tubular damage have revealed no evidence of inulin leakage 3-4 wk after the simultaneous injection of potassium dichromate and mercuric chloride (16) or $144 \mathrm{~h}$ after aminonucleoside administration (48).

In any event only a very small number of the micropuncture collections here reported were from tubules with high pressure and very slow flow rates and hence possibly suspect in regards to transtubular inulin leakage. Exclusion of these few data in no way controverts our conclusions about nephron heterogeneity.

Structural and functional heterogeneity among nephrons in the chronically diseased kidney was first described by Oliver, Bloom, and MacDowell in 1941 (12) using specific histological staining techniques in spontaneous chronic canine glomerulonephritis. More recently micropuncture studies in rats with chronic pyelonephritis (13), heavy metal poisoning (16), and anti-GBM nephritis (17) have confirmed this marked functional heterogeneity. From the detailed single nephron observations reported in the present study, together with those previously described, we believe that there can now be no doubt that single nephrons in the experimental chronically diseased kidney show marked heterogeneity both in function and structure.

Each superficial nephron studied, however, demonstrated almost the same glomerulotubular balance, absolute reabsorption to the late proximal convolution 

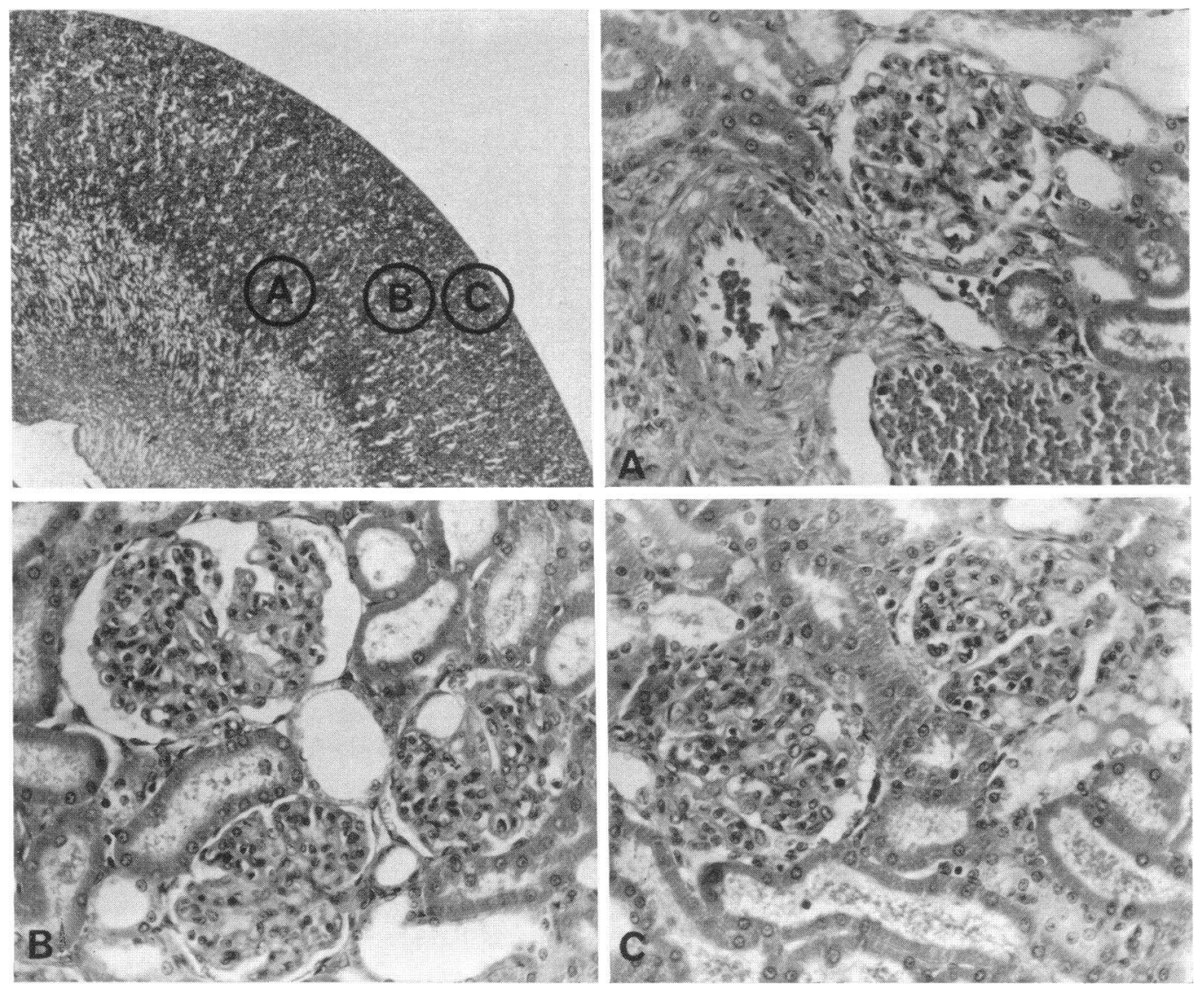

FIGURE 12 The uniformity of glomerular proliferative changes are seen at various levels through the cortex in a rat with experimental anti-GBM glomerulonephritis. A glomerulus adjacent to an arcuate artery and vein (A), three glomeruli in the mid-cortex (B), and two glomeruli in the superficial cortex (C) are seen. Hematoxylin-eosin stain. A-C, $\times 220$.

varying in direct proportion to the nephron filtration rate at all levels from 5 to $93 \mathrm{nl} / \mathrm{min}$. Similar maintenance of single nephron glomerulotubular balance despite marked heterogeneity of filtration rates has also been found by Rocha et al. (17) in rats with antiGBM nephritis, except in those nephrons with low filtration rates $(25 \mathrm{nl} / \mathrm{min})$ when $\mathrm{F} / \mathrm{P}$ inulin levels were unusually high. Important implications concerning the mechanism(s) regulating glomerulotubular balance in the diseased nephron follow from our observations, since such a mechanism(s) must obviously work on a single nephron basis.

There has recently been great interest in the role of the so called peritubular physical factors (i.e., hydrostatic and oncotic pressure in the tubular environment) in controlling tubular reabsorption. Experimental variation of peritubular capillary hydrostatic or oncotic forces can apparently alter proximal reabsorptive rates $(49,50)$. For these factors to be important in the setting of glomerulotubular balance in single nephrons in our heterogeneous diseased kidneys it must first be shown that each proximal tubule is surrounded only by peritubular capillaries from its own efferent arteriole, since the oncotic pressure in each efferent arteriole will initially be dependent on that nephron's FF. There are comparatively few detailed anatomical studies of vascular-tubular relationships. Some evidence of a close relationship between each efferent arteriole and its own proximal tubule has been reported recently by Steinhausen, Eisenbach, and Galaske (51) in the rat kidney and by Beeuwkes (52) in the superficial cortex of the dog kidney. Both agree however that there are many free communications between the peritubular capillaries. On direct microscopic examination of the living kidney these appear to form a freely anastomotic network. Also, it might be supposed that nephrons with high intratubular pressures and low filtration rates should have adjacent peritubular capillaries with similar high hydrostatic pressures, assuming that this force could influence transport across the proximal tubule. Inter- 
stitial fluid pressure remains unknown, and since it is presumably the gradient between this compartment and the peritubular capillary on the one hand and the proximal tubule on the other which would determine reabsorptive rates, absolute peritubular capillary pressures may not be of importance. Although a significantly increased variability in efferent arteriole and peritubular capillary hydrostatic pressures was found in the diseased kidney compared with controls, the highest values found did not exceed normal limits. Indeed, we were impressed by the finding of postglomerular vessels with very low hydrostatic pressures. This observation was predicted by Bradley (53) because of the marked obstructive disease of the glomerular vessels found in glomerulonephritis. We therefore find it difficult to accept that the reabsorptive rate per nephron is influenced solely by that nephron's peritubular "physical" environment in the absence of evidence that it is specific for individual nephrons.

Secondly, it has been suggested that SNGFR might be regulated within individual nephrons by a tubularvascular feedback system involving the renin-angiotensin system, such that an increase in sodium delivery to the macula densa might result in increased renin production and hence angiotensin release which in turn would so alter afferent or efferent vascular resistance to result in a fall in GFR (54-56). Recent studies have shown that GFR calculated from distal tubular fluid collections are consistently lower than those calculated from proximal tubular fluid collections in that nephron, when distal tubular sodium concentration are presumably very low due to the proximal oil block $(57,58)$. Others have failed to substantiate these findings (59). All our tubular fluid collections were made in proximal tubules after placing an oil block of at least 4-5 tubule diameters in length distal to the collection pipette. Despite complete blocking of the tubular fluid flow beyond this point, however, marked heterogeneity of single nephron filtration rate with maintenance of glomerulotubular balance was found.

One of the earliest and simplest proposals made to explain the phenomenon of glomerulotubular balance was that some factor(s) related to proximal intraluminal load determined tubular absorption, completely independent of peritubular environment $(60,61)$. In vitro and in vivo single nephron microperfusion studies, however, suggested that glomerulotubular balance was not an intrinsic property of the proximal tubule, since experimental alteration of proximal tubule perfusion rates with artificial perfusates did not result in any significant change in absolute reabsorptive rates $(62,63)$. It is also now accepted that intratubular volume (64) is not the primary determinant of proxi- mal reabsorptive rate $(65,66)$. Recently, however, Bartoli, Conger, and Earley (59), using a partial proximal tubule collection technique, have found that a fall in the delivery rate of normal filtrate along the proximal tubule is associated with a decrease in the absolute reabsorptive rate. They suggest that this might be due either to variation in the mixing of unstirred diffusion layers or to a change in the availability of some ultrafilterable plasma constituent with change in intraluminal flow rates. Similarly in our studies it is possible that some factor or factors related to proximal intraluminal flow or load was responsible for appropriate alignment of absolute reabsorptive rate in individual nephrons with widely differing filtration rates.

Marked heterogeneity of SNGFR was found in both models of glomerulonephritis, but more especially in the AICN group. Also mean SNGFR was significantly lower in the acute proliferative anti-GBM antibodyinduced glomerulonephritis than in the AICN rats with chronic membranous glomerulonephritis. No "supernephrons" with very high filtration rate was found in anti-GBM nephritis, a finding similar to that of Rocha et al. (17). This probably reflects the acute diffuse involvement of glomeruli in this model. In contrast, the much greater heterogeneity of SNGFR in AICN rats probably was related to the chronicity of the experimental model allowing adequate time for adaptation of nephron function.

The primary factors influencing individual GFR, i.e. afferent and efferent EFP, RPF, permeability and surface area of glomerular capillary bed available for filtration, are complex and are presumably altered in the diseased glomerulus. Recently, advances in micropuncture technology and finding of accessible superficial glomeruli in a mutant strain of Wistar rats has enabled direct study of these factors $(32,67)$. It has been shown that in the normal superficial rat glomerulus $\mathrm{Pg}$ are lower than previously supposed and that, filtration equilibrium is generally reached under a variety of experimental conditions (68). We have attempted to study these factors indirectly in the diseased nephron.

Firstly, no consistent relationship was found between SNGFR and proximal intratubular hydrostatic pressure in either AICN or anti-GBM nephritis, although a tendency toward lower SNGFR in nephrons with higher intratubular pressures was seen in AICN rats. These latter nephrons appeared dilated and were presumably blocked downstream by fibrosis or proteinaceous debris and casts.

Secondly, we found a positive correlation between calculated $\mathrm{Pg}$ and SNGFR, but this was statistically significant only for animals with anti-GBM disease. $\mathrm{Pg}$ was calculated as the sum of the directly determined 
stop flow pressure and the afferent oncotic pressure $(69,28)$. This calculation involves three important assumptions, none of which is as yet directly proven. First, glomerular filtration must be completely stopped so that the protein concentration in the systemic circulation can be taken as the efferent anteriolar protein concentration. Secondly, any possible effect of reduction of flow at the macula densa after blockage of the nephron with oil is negligible. Thirdly, appropriate alterations in afferent/efferent arteriolar resistance must have occurred in order to accommodate the increased capillary flow due to cessation of filtration without change in glomerular hydrostatic pressure. That the latter can occur under certain circumstances has been shown by Brenner, Troy, Daugharty, Deen, and Robertson (68) when a $100 \%$ increase in glomerular capillary plasma flow due to plasma volume expansion resulted in a change in directly measured $\mathrm{Pg}$ of only 1.8 $\mathrm{mm} \mathrm{Hg}$. Values reported for stop flow pressures in hydropenic adult rats from different laboratories have varied considerably, from 26 to $29 \mathrm{~mm} \mathrm{Hg}(17,70)$ to $55 \mathrm{~mm} \mathrm{Hg}$ (69), most values lying between 32 and $40 \mathrm{~mm} \mathrm{Hg}$. In our studies the mean value calculated for $\mathrm{Pg}$ from stop flow pressure measurements in control rats was $47.4 \mathrm{~mm} \mathrm{Hg}$, which is similar to that reported by Blantz, Israelit, Rector, and Seldin (67) obtained by using direct capillary punctures in hydropenic "Munich" Wistar rats with superficial glomeruli (47.4 $\mathrm{mm} \mathrm{Hg}$ ), but slightly higher than that reported by Brenner, Troy, and Daugharty (32) (44.4 mm Hg) in similar animals. Calculated mean $\mathrm{Pg}$ was significantly higher in both AICN and anti-GBM nephritic kidneys than in controls, a finding different than that of Rocha et al. (17) who reported a lower calculated mean glomerular capillary pressure in rats with antiGBM nephritis than in control animals. Measurements made by Rocha et al. were at random points in the proximal tubule and stop flow pressures are lower by, on average, $7 \mathrm{~mm} \mathrm{Hg}$, when measured in late proximal rather than early proximal convolutions (28). Obviously direct measurements of hydrostatic pressure in superficial diseased glomeruli are required. It is possible that a significant fall in hydrostatic pressure occurs due to increased resistance in the damaged capillary bed in experimental glomerulonephritis. Furthermore, the hemodynamic changes occurring in damaged glomerular capillary beds during stop flow are also unknown and may differ from that seen under normal conditions.

Thirdly, it seems safe to assume that the filtration characteristics of the GBM may be altered to different extents in the two histologically different models of glomerular injury under study. Thus we found that although the mean calculated $\mathrm{Pg}$ was similar in both AICN and anti-GBM nephritis, mean SNGFR was significantly lower in those animals with anti-GBM disease. This suggests a decrease either in glomerular permeability or in blood flow due to luminal encroachment in anti-GBM rats. Histologically the $A I C N$ rats have uniformly thickened GBM and large amounts of immune complex ( $\operatorname{gg}, \mathrm{C} 3$ ) deposits in the absence of an obvious acute phlogogenic response. By electron microscopy, these immune complex deposits appear as electron-dense masses under the fused epithelial cell foot processes, giving the GBM a rather uniform thickened appearance $(71,72)$. The administration of antiGBM antibodies, on the other hand, produced a more acute proliferative response with polymorphonuclear leukocyte infiltration and very early (within hours) changes in glomerular permeability as manifested by proteinuria. Indeed, gaps have been identified in the GBM by electron microscopy (73) and fragments of the GBM have been detected in the urine (74). Little is known about the functional characteristics of the remaining somewhat irregular GBM ; however, our observations would suggest that its usefulness as an ultrafilter is impaired.

Fourthly, in AICN and anti-GBM disease there was a direct relationship between SNGFR and both afferent EFP, obtained by direct measurement of stop flow pressure and intratubular free flow pressure, and calculated efferent EFP. Nephrons with high filtration rates had high afferent and efferent EFP and did not apparently reach filtration equilibrium. Only those with very low filtration rates came near to equilibrium. In control rats, mean efferent filtration pressure was significantly lower than in the diseased kidney, but filtration equilibrium did not appear to be reached. Before speculating on the significance of these observations it should be noted that the calculation of efferent EFP is dependent on estimation of the efferent oncotic pressure which we obtained using the whole kidney FF and the afferent protein concentration. Whole kidney FF in our control rat kidneys was 0.22 , lower than that generally reported in hydropenic adult rats. Assuming that the estimated $\mathrm{Pg}$ is correct, we calculate that for these animals to reach filtration equilibrium an FF of approximately 0.38 would be required. In the diseased rats whole kidney FF were much lower. FF of individual glomeruli were not measured. If one assumes a fairly constant glomerular capillary plasma flow per nephron, then nephrons with high filtration rates would have significantly higher FF than those with low SNGFR, perhaps resulting in a smaller disequilibrium at the end of the glomerular capillary bed. More likely, however, both plasma flows and FF in 
individual glomeruli are variable in the diseased kidney. Resolution of these problems obviously awaits measurements of single nephron FF in diseased glomeruli.

Finally, the possible contribution of immunologic tubular damage to derangement of single nephron function should be considered. Previous morphologic studies have described tubular abnormalities in AICN (40), and tubular abnormalities often considered secondary to glomerular damage are universal in advancing experimental and human glomerulonephritis. No clearcut immunologic role has been established for these lesions; however, certain observations would suggest that immune tubular as well as glomerular injury does occur in these diseases. Tubular deposits of immunoglobulin and complement have been observed in experimental and human renal disease (75-77). Human antiGBM nephritis frequently has linear deposits of IgG in the TBM suggesting the presence of anti-TBM antibodies as well. We have in addition observed the presence of anti-TBM antibodies in renal allografts with specificity restricted to the TBM on elution studies (Wilson, unpublished observations). Irregular granular deposits of IgG and C3 are commonly seen in renal tubules (often associated with the TBM) of patients with immune complex glomerulonephritis, particularly when nearing endstage (Wilson, unpublished observations). The significance of these deposits is as yet unknown. It is not surprising therefore that immunopathologic tubular abnormalities would be present in our experimental models. The AICN rats had evidence of IgG and C3 deposits on the brush border as well as intracellularly accompanied by apparent stripping of the PAS-positive brush border of the proximal tubules by cells within the tubular lumen, suggesting immunopathologically induced tubular injury. No direct immunofluorescent evidence of immune deposits was found in the anti-GBM rats. These observations correlated directly with the difference in $\mathrm{PAH}$ extraction observed in the two models in which only the AICN rats had a significant decrease in this monitor of tubular function.

\section{ACKNOWLEDGMENTS}

This study was supported by a grant-in-aid from the American Heart Association, by grant HE-02334 from the National Institutes of Health, by Public Health Service Contract $\mathrm{PH}$ 43-68-621 and by U. S. Public Health Service grant A 1-07007. Scripps Publication Number 720.

\section{REFERENCES}

1. Earle, D. P., Jr., J. V. Taggart, and J. A. Shannon. 1944. Glomerulonephritis. A survey of the functional organization of the kidney in various stages of diffuse glomerulonephritis. J. Clin. Invest. 23 : 119.
2. Bradley, S. E., G. P. Bradley, C. J. Tyson, J. J. Curry, and W. D. Blake. 1950. Renal function in renal diseases. Am. J. Med. 9 : 766.

3. Kleeman, C. R., R. Okun, and R. J. Heller. 1966. The renal regulation of sodium and potassium in patients with chronic renal failure (CRF) and the effect of diuretics on the excretion of these ions. Ann. N. Y. Acad. Sci. 139: 520.

4. Brod, J. 1971. Study of renal function in the differential diagnosis of kidney disease. Br. Med. J. 3: 135.

5. Lewy, J. E., L. Salinas-Madrigal, P. B. Herdson, C. L. Pirani, and J. Metcoff. 1971. Clinico-pathologic correlations in acute post streptococcal glomerulonephritis. Medicine (Baltimore). 50: 453.

6. Oliver, J. 1939. Architecture of the kidney in chronic Bright's disease. Paul B. Hoeber Inc., New York. 1939.

7. Oliver, J. 1950. When is the kidney not a kidney? J. Urol. $63: 373$.

8. Platt, R. 1952. Structural and functional adaptation in renal damage. Br. Med. J. 1: 1313 and 1372 .

9. Pitts, R. F. 1963. Physiology of the kidney and body fluids. Year Book Medical Publishers, Chicago. 1st edition.

10. Bricker, N. S., S. Klahr, H. Lubowitz, and R. E. Rieselbach. 1965. Renal function in chronic renal disease. Medicine (Baltimore). 44: 263.

11. Gottschalk, C. W. 1971. Function of the chronically diseased kidney. The adaptive nephron. Circ. Res. 11 Suppl. II: 1.

12. Oliver, J., F. Bloom, and M. MacDowell. 1941. Structural and functional transformations in the tubular epithelium of the dog's kidney in chronic Bright's disease and their relation to mechanisms of renal compensation and failure. J. Exp. Med. 73: 141.

13. Bank, N., H. S. Aynedjian. 1966. Individual nephron function in experimental bilateral pyelonephritis. I. Glomerular filtration rate and proximal tubular sodium, potassium and water reabsorption. J. Lab. Clin. Med. $68: 713$.

14. Lubowitz, H., M. L. Purkerson, and N. S. Bricker. 1966. Investigation of single nephrons in the chronically diseased (pyelonephritic) kidney of the rat using micropuncture techniques. Nephron. 3: 73.

15. Lubowitz, H., M. L. Purkerson, M. Sugita, and N. S. Bricker. 1969. GFR per nephron and per kidney in chronically diseased (pyelonephritic) kidney of the rat. Am. J. Physiol. $217: 853$.

16. Kramp, R., C. W. Gottschalk, J. Oliver, and M. MacDowell. 1970. Micropuncture and microdissection studies of damaged rat kidneys. Clin. Res. 18: 544.

17. Rocha, A., M. Marcondes, and G. Malnic. 1973. Micropuncture study in rats with experimental glomerulonephritis. Kidney Int. 3 : 14.

18. Heymann, W., D. B. Hackel, S., Harwood, S. G. F. Wilson, and J. L. P. Hunter. 1959. Production of nephrotic syndrome in rats by Freund's adjuvants and rat kidney suspensions. Proc. Soc. Exp. Biol. Med. $100: 660$.

19. Edgington, T. S., R. J. Glassock, and F. J. Dixon. 1967. Autologous immune-complex pathogenesis of experimental allergic glomerulonephritis. Science (Wash. D. C.). 155 : 1432.

20. Unanue, E. R., and F. J. Dixon. 1967. Experimental glomerulonephritis: immunological events and pathogenetic mechanisms. Adv. Immunol. 6: 1 . 
21. Edgington, T. S., R. J. Glassock, and F. J. Dixon. 1969. Autologous immune complex nephritis induced with renal tubular antigen. I. Identification and isolation of the pathogenic antigen. J. Exp. Med. 127: 555.

22. Krakower, C. A., and S. A. Greenspon. 1951. Localization of the nephrotoxic antigen within the isolated renal glomerulus. Arch. Pathol. 51: 629.

23. Pressman, D., E. D. Day, and M. Blau. 1957. The use of paired labeling in the determinations of tumorlocalizing antibodies. Cancer Res. $17: 845$.

24. Unanue, E. R., and F. J. Dixon. 1965. Experimental glomerulonephritis. V. Studies on the interaction of nephrotoxic antibodies with tissues of the rat. J. Exp. Med. $121: 697$

25. Unanue, E. R., and F. J. Dixon. 1965. Experimental glomerulonephritis. VI. The autologous phase of nephrotoxic serum nephritis. J. Exp. Med. 121: 715 .

26. Gottschalk, C. W., and M. Mylle. 1956. Micropuncture study of pressures in proximal tubules and peritubular capillaries of the rat kidney and their relation to ureteral and venous pressures. Am. J. Physiol. 185: 430.

27. Allison, M. E. M., E. M. Lipham, W. E. Lassiter, and C. W. Gottschalk. 1973. The acutely reduced kidney. Kidney Int. $3: 354$.

28. Allison, M. E. M., E. M. Lipham, and C. W. Gottschalk. 1972. Hydrostatic pressure in the rat kidney. Am. J. Physiol. 223: 975.

29. Daugharty, T. M., I. F. Ueki, D. P. Nicholas, and B. M. Brenner. 1972. Comparative renal effects of isoncotic and colloid-free volume expansion in the rat. Am. J. Physiol. 222 : 225-233.

30. Brenner, B. M., K. H. Falchuk, R. I. Keimowitz, and R. W. Berliner. 1969. The relationship between peritubular capillary protein concentration and fluid reabsorption by the renal proximal tubule. J. Clin. Invest. 48 : 1519 .

31. Landis, E. M., and J. R. Pappenheimer. 1963. Exchange of substances through capillary walls. Handb. Physiol. Sect. 2 (Circulation). 2 : 961.

32. Brenner, B. M., J. L. Troy, and T. M. Daugharty. 1971. The dynamics of glomerular ultrafiltration in the rat. J. Clin. Invest. 50: 1776.

33. Lewy, J. E., and A. Pesco. 1973. Micropuncture study of albumin transfer in aminonucleoside nephrosis in the rat. Pediatr. Res. $7: 553$.

34. Oken, D. E., S. C. Cotes, and C. W. Mende. 1972. Micropuncture study of tubular transport of albumin in rats with aminonucleoside nephrosis. Kidney Int. 1: 3.

35. Gottschalk, C. W., F. Morel, and M. Mylle. 1965. Tracer microinjection studies of renal tubular permeability. Am. J. Physiol. 209: 173.

36. Wilson, C. B., and F. J. Dixon. 1973. Anti-glomerular basement membrane antibody-induced glomerulonephritis. Kidney Int. 3 : 74.

37. Wilson, C. B., and F. J. Dixon. 1970. Antigen quantitation in experimental immune complex glomerulonephritis. I. Acute serum sickness. J. Immunol. 105: 279.

38. Perry, S. W. 1965. Proteinuria in the Wistar rat. $J$. Pathol. Bacteriol. 89 : 729.

39. Hess, E. V., C. T. Ashworth, and M. Ziff. 1965. Nephrosis in the rat induced by rat kidney extracts. Ann. N. Y. Acad. Sci. 124: 323.

40. Cortney, M. A., M. Mylle, W. E. Lassiter, and C. W. Gottschalk. 1965. Renal tubular transport of water, solute and $\mathrm{PAH}$ in rats loaded with isotonic saline. Am. J. Physiol. 209 : 1199.

41. Klassen, J., T. Sugisaki, F. Milgrom, and R. T. McCluskey. 1971. Studies on multiple renal lesions in Heyman's nephritis. Lab. Invest. $25: 577$.

42. Berg, B. N. 1967. Longevity studies in rats. II. Pathology of ageing rats. In Pathology of Laboratory Rats and Mice. E. Cotchin and F. J. C. Roe, editors. F. A. Davis Co., Philadelphia. 749.

43. Wilson, C. B., and F. J. Dixon. 1974. Immunologic mechanisms in the pathogenesis of glomerulonephritis. In Controversy in Internal Medicine II. F. J. Ingelfinger, M. Finland, A. S. Relman, and R. H. Ebert, editors. W. B. Saunders Co., Philadelphia. 685.

44. Naruse, T., K. Kitamura, Y. Miyakawa, and S. Shibata. 1973. Deposition of renal tubular epithelial antigen along the glomerular capillary walls of patients with membranous glomerulonephritis. J. Immunol. 110: 1163.

45. Brun, C., T. Hilden, and F. Raaschou. 1949. Physiology of diseased kidney: determination of glomerular filtration, renal blood flow and maximal tubular excretory capacity and their contribution to the understanding of function of diseased kidney. Acta Med. Scand. Suppl. 234: 7.1.

46. Allison, M. E. M., and A. C. Kennedy. 1971. Diuretics in chronic renal disease. A study of high dosage frusemide. Clin. Sci. (Oxf.). 41: 171.

47. Heymann, W., and H. Z. Lund. 1951. Nephrotic syndrome in rats. Pediatrics. $7: 691$.

48. Lewy, J. E., and A. Pesce. 1973. Microinjection study of inulin and albumin transfer in aminonucleoside nephrosis in the rat. Am. Soc. Nephrology. 65.

49. Lewy, J. E., and E. E. Windhager. 1968. Peritubular control of proximal tubular fluid reabsorption in the rat. Am. J. Physiol. 214: 943.

50. Brenner, B. M., and J. L. Troy. 1971. Postglomerular vascular protein concentration: evidence for a causal role in governing fluid reabsorption and glomerulotubular balance by the renal proximal tubule. J. Clin. Invest. 50: 336

51. Steinhausen, M., G. M. Eisenbach, and R. Galaske. 1970. Countercurrent system in the renal cortex of rats. Science (Wash. D. C.). 167: 1631.

52. Beeuwkes, R., III. 1971. Efferent vascular patterns and early vascular-tubular relations in the dog kidney. Am. J. Physiol. 221 : 1361.

53. Bradley, S. E. 1944. Medical progress. Modern concepts of renal structure and function in chronic Bright's disease. N. Engl. J. Med. 231: 421.

54. Thurau, K., and J. Schnermann. 1965. Die Natriumkonzentration an den Macula densa-Zellen als regulierender Faktor für das Glomerulumfiltrat (Mikropunktionsversuche). Klin. Wochenschr. 43: 410.

55. Schnermann, J., A. E. G. Persson, and B. Agerup. 1973. Tubuloglomerular feedback. Nonlinear relation between glomerular hydrostatic pressure and loop of Henle perfusion rate. J. Clin. Invest. 52: 862.

56. Schnermann, J., F. S. Wright, J. M. Davis, W. V. Stackelberg, and G. Grill. 1970. Regulation of superficial nephron filtration rate by tubulo-glomerular feedback. Pfiugers Arch. Eur. J. Physiol. 318: 147.

57. Schnermann, J., J. M. Davis, P. Wunderlich, D. Z. Levine, and M. Horster. 1971. Technical problems in the micropuncture determination of nephron filtration 
rate and their functional implications. Pflügers Arch. Eur. J. Physiol. 329: 307.

58. Navar, L. G., T. J. Burke, R. R. Robinson, and J. R. Clapp. 1973. Role of distal delivery in regulation of nephron filtration rate. Clin. Res. 21: 701.

59. Bartoli, E., J. D. Conger, and L. E. Earley. 1973. Effect of intraluminal flow on proximal tubular reabsorption. J. Clin. Invest. 52: 843.

60. Kelman, R. B. 1962. A theoretical note on experimental flow in the proximal part of the mammalian nephron. Bull. Math. Biophys. 24: 303.

61. Wiederholt, M., K. Hierholzer, E. E. Windhager, and G. Giebisch. 1967. Microperfusion study of fluid reabsorption in proximal tubules of rat kidney. Am. J. Physiol. 213: 809.

62. Morgan, T., and R. W. Berliner. 1969. In vivo perfusion of proximal tubules of the rat: glomerulotubular balance. Am. J. Physiol. 217 : 992.

63. Burg, M. B., and J. Orloff. 1968. Control of fluid absorption in the renal proximal tubule. J. Clin. Invest. $47: 2016$.

64. Gertz, K. H., J. A. Mangos, G. Braun, and H. D. Pagel. 1965. On the glomerular tubular balance in the rat kidney. Pfiugers Arch. gesamte Physiol. Menschen Tiere. 285 : 360.

65. Arrizurieta-Muchnik, E. E., W. E. Lassiter, E. M. Lipham, and C. W. Gottschalk. 1969. Micropuncture study of glomerulotubular balance in the rat kidney. Nephron. 6: 418.

66. Rodico, J., J. Herrera-Acosta, J. C. Sellman, F. C. Rector, Jr., and D. W. Seldin. 1969. Studies on glomerulotubular balance during aortic constriction, ureteral obstruction, and venous occlusion in hydropenia and saline-loaded rats. Nephron. 6: 437.

67. Blantz, R. C., A. H. Israelit, F. C. Rector, Jr., and D. W. Seldin. 1972. Relation of distal tubular $\mathrm{NaCl}$ delivery and glomerular hydrostatic pressure. Kidney Int. 2: 22.

68. Brenner, B. M., J. L. Troy, T. M. Daugharty, W. M.
Deen, and C. R. Robertson. 1972. Dynamics of glomerular ultrafiltration in the rat. II. Plasma-flow dependence of GFR. Am. J. Physiol. 223: 1184.

69. Gertz, K. H., J. A. Mangos, G. Braun, and H. D. Pagel. 1966. Pressure in the glomerular capillaries of the rat kidney and its relation to arterial blood pressure. Pflügers Arch. gesamte Physiol. Menschen Tiere. $288: 369$.

70. Hayslett, J. P., D. T. Domoto, M. Kashgarian, and F. H. Epstein. 1970. Role of physical factors in the natriuresis induced by acetylcholine. Am. J. Physiol. 218: 880 .

71. Alousi, M. A., R. S. Post and W. Heymann. 1969. Experimental autoimmune nephrosis in rats. Morphogenesis of the glomerular lesion: immunohistochemical and electron microscopic studies. Am. J. Pathol. 54: 47.

72. Laguens, R., and A. Segal. 1969. Experimental autologous immune-complex nephritis. An electron microscope and immunohistochemical study. J. Exp. Mol. Pathol. $11: 89$.

73. Gang, N. F., E. Trachtenberg, J. Allerhand, N. Kalant, and W. Mautner. 1970. Nephrotoxic serum nephritis. III. Correlation of proteinuria, excretion of glomerular basement membrane-like protein and changes in ultrastructure of the glomerular basement membrane as visualized by lanthanum. Lab. Invest. 23: 436.

74. Hawkins, D., and C. G. Cochrane. 1968. Glomerular basement membrane damage in immunological glomerulonephritis. Immunology. 14: 665 .

75. Klassen, J., G. A. Andres, J. C. Brennan, and R. T. McCluskey. 1972. An immunologic renal lesion in man. Clin. Immunol. Immunopathol. 1: 69.

76. Unanue, E. R., F. J. Dixon, and J. D. Feldman. 1967. Experimental allergic glomerulonephritis induced in the rabbit with homologous renal antigens. J. Exp. Med. 125 : 163.

77. Germuth, F. J., Jr., and E. Rodriquez. 1973. Immunopathology of the Renal Glomerulus. Little, Brown and Company, Boston. 129. 